\title{
Long-Term Relationships between the Marine Environment, Krill and Salps in the Southern Ocean
}

\author{
Chung Il Lee, ${ }^{1,2}$ Evgeny Pakhomov, ${ }^{1}$ Angus Atkinson, ${ }^{3}$ and Volker Siegel ${ }^{4}$ \\ ${ }^{1}$ Department of Earth and Ocean Sciences, 6339 Stores Road, University of British Columbia, Vancouver, BC, Canada V6T 1Z4 \\ ${ }^{2}$ Laboratory of Fisheries Oceanography, Faculty of Marine Bioscience and Technology, Gangneung-Wonju National University, \\ 120 Gangneung Daehangno, Gangneung 210-702, Republic of Korea \\ ${ }^{3}$ British Antarctic Survey, Natural Environment Research Council, High Cross, Cambridge CB3 OET, UK \\ ${ }^{4}$ Sea Fisheries Institute, Palmaille 9, 22767 Hamburg, Germany
}

Correspondence should be addressed to Chung Il Lee, leeci@gwnu.ac.kr

Received 1 June 2010; Revised 5 August 2010; Accepted 21 November 2010

Academic Editor: Wen-Xiong Wang

Copyright ( $) 2010$ Chung Il Lee et al. This is an open access article distributed under the Creative Commons Attribution License, which permits unrestricted use, distribution, and reproduction in any medium, provided the original work is properly cited.

Long-term variations (1975-2002) in climatology of marine environmental parameters, Antarctic krill, Euphausia superba, and the pelagic tunicate, Salpa thompsoni, were compared within the Atlantic Sector of the Southern Ocean. Sea water temperature in the top $400 \mathrm{~m}$ increased at a rate of $0.020-0.030^{\circ} \mathrm{C} \cdot \mathrm{yr}^{-1}$, which was accompanied by the dissolved oxygen decline. Top $100 \mathrm{~m}$ water layer became fresher with lower concentrations of phosphates and nitrates, while at subsurface layers (200-400 m) both salinity and nutrients showed small increasing trend. Unlike phosphates and nitrates, silicate concentrations decreased in the entire water column. Shorter-term water temperature dynamics closely correlated with the El Nino events expressed as the Southern Oscillation Index which in turn was linked to the propagation of the Antarctic Circumpolar Wave (ACW). The variations of sea-ice extent matched well the changes in both air and water temperatures. In general, abundance of krill and salps showed opposite to each other trends. Due to large area considered in this study, no significant relationships between abiotic factors and both krill and salps were found. However, our analysis demonstrated that krill abundance was greater in years with lower sea water temperature, greater sea-ice extent and higher nutrient concentration, while salps showed the opposite pattern.

\section{Introduction}

Antarctic krill Euphausia superba and the pelagic tunicate Salpa thompsoni are regarded as two of the most important filter-feeding species of the Southern Ocean, ranking second and third after copepods in terms of total dry biomass [1]. While krill is an important food source for many top predators and subject to a fishery [2], salps represent more of "nuisance" species, with explosive population increases under some conditions. At these times, salps can dominate the plankton, leading to the scarcity of other zooplankters. Until recently, salps were considered to be a trophic " $\mathrm{cul}$ de-sac" but important grazers, channeling organic matter to the ocean interior via rapidly sinking fecal pellets [3-5]. However, more recent work [6] has shown that they are also eaten by a range of fish and seabirds.
The circumpolar-scale distribution of Antarctic krill is now relatively well documented $[1,7,8]$. The distribution is strongly asymmetrical, with over $75 \%$ of the population concentrated into the sector $0^{\circ}-90^{\circ} \mathrm{W}$, a sector of elevated food concentrations [9]. Despite the preponderance of krill research, increased attention has been paid to pelagic tunicates, especially since the studies in [10] re-emphasized their importance in total Antarctic zooplankton biomass. Salps are primarily oceanic, have a more even circumpolar distribution, not ice-dependent like krill, and are generally found at lower food concentrations than krill [6, 11-13].

Over the past century, a warming trend has been demonstrated for the Antarctic Peninsula region and around South Georgia [14-16] and to a lesser extent for the entire Southern Ocean $[17,18]$. This is linked to a decrease in area and seasonal extent of sea-ice cover [19-21]. On the global 
scale, this probably is related to a global trend as the World Ocean has warmed by $0.037^{\circ} \mathrm{C}$ during the last 50 years $[17,22]$.

Against a background of Southern Ocean warming, the abundance and distribution of krill and salps have shown evidence for change over the last century. Krill densities in the SW Atlantic sector decreased $[8,23]$, while the abundance of the warmer water species, Salpa thompsoni, increased in the high-latitude part of its circumpolar range $[6,8]$. The extent to which these changes are bottom-up or top down controlled is being debated [24, 25], as indeed are the detailed mechanisms for population control of both species $[6,26,27]$.

Interactions between krill and salps have also suggested to influence their abundance and have been interpreted in a variety of ways, according to the scale of the observation. These include competitive exclusion [23], direct predation [28], and larger-scale biotopic segregation $[6,10]$. However, it is now well documented that south of the Antarctic Polar Front, Antarctic krill and salps may overlap in their distributions on macro- and mesoscales [6, 8, 23, 29, 30]. At smaller scales, both species may utilize vertical and horizontal water structures probably decreasing competition/predation and increasing their fitness [31-33].

Although long-term changes in krill and salp densities and distribution have been documented, it is still not clear what is driving these changes. The main aims of this paper were therefore to illustrate and compare the long- and shortterm trends (variations) of the oceanic condition climatology as well as climatology of Antarctic krill and salp densities. The Atlantic sector of the Southern Ocean was selected for this study for two reasons. First, it contains over half of the total krill population and also has dense concentrations of salps $[6,8,9,11]$. Secondly, this sector has the best data coverage, of data across all trophic levels, of any sector of the Southern Ocean.

\section{Materials and Methods}

2.1. World Ocean Database 2001 and 2005. Hydrographic data for analysis of water masses in this study area were collected from the World Ocean Database 2001 and 2005 (WOD01, http://www.nodc.noaa.gov/, http://www.nodc.noaa.gov/OC5/WOD05/pr_wod05.html, http://www.nodc.noaa.gov/OC5/WOD05/updates05.html) offered by the National Oceanographic Data Center (Figure 1). WOD05 is an update of WOD01 that houses climatological data at standard depths within the World Meteorological Organization (WMO) square. A WOD05 release contains additional profiles of temperature and salinity from a new ocean profiling instrument [34] and significantly updated with the post-1995 data, especially between $50^{\circ} \mathrm{S}$ and $80^{\circ} \mathrm{S}$, compared to WOD01. Nevertheless, the latter supports some data for the period 1970-1980s that are not included into WOD05. Therefore, in this paper both data sets were utilized. The WOD01 and WOD05 contain data measured from various instrument types shown in Table 1 and various countries, and the OSD, CTD, MBT, XBT, PFL datasets are available in the study [35].
These datasets from the WOD01 and WOD05 were compiled together for making the most complete set of historical ocean profile data. Further details of the WOD01 and WOD05 database are available at http://www.nodc.noaa.gov/.

Sea water temperature, salinity, dissolved oxygen, phosphate, nitrate, and silicate concentrations at standard depths between South America and Antarctic Peninsula were extracted from WOD01 and WOD05 for the period from 1973 to 2002. Each parameter extracted was averaged to calculate climatology across the whole study area for every austral summer season (January-March) at a hundred meter interval from surface to $400 \mathrm{~m}$, for example, 0, 100, 200, 300, $400 \mathrm{~m}$ under the assumption that krill and salps were largely concentrated during the summer in the upper $400 \mathrm{~m}$ water layer [6].

Many studies $[14,15,24,36]$ report that the World Ocean, including the Antarctic Ocean, has become warmer. To illustrate this, vertical sections of the 5-year mean sea water temperatures from surface to $500 \mathrm{~m}$ depth within the special box of $50-65^{\circ} \mathrm{S}$ and $59-65^{\circ} \mathrm{W}$ for the period from 1975 to 2002, for example, 1975-1979, 1980-1984, 19851989, 1990-1994, 1995-1999, and 2000-2002 (only 3 years), were prepared. In addition, to illustrate the variations of water masses during the summer season (from January to March) in the Southern Ocean, T-S diagrams showing origin and mixing among water masses were also plotted for the same 5-year periods.

2.2. Sea-Ice Index and Air Temperature. Sea-ice has an important role in providing shelter and food to Antarctic zooplankton including krill larvae [27, 37, 38], and its area and extent may also be affected by atmospheric conditions and sea water temperature. Annual mean sea-ice extent data which was the average latitude of maximum, for example, the northernmost latitude of the sea ice edge, from 1979 to 2002 in the study area $\left(50-70^{\circ} \mathrm{S}, 20-80^{\circ} \mathrm{W}\right)$ were obtained from [39] Australian Antarctic Data Centre (2005, http://data.aad.gov.au/aadc/envi/search_ice_extent.cfm). Annual mean surface air temperature data from South Georgia were taken from [40] for the same (1979-2002) period. This surface air temperature dataset comprises 1224 monthly grids of observed air temperature for the period 1901-2002 and cover the global land surface at $0.5^{\circ}$ resolution. Annual means of the winter sea-ice extent and air temperature were calculated and compared with the time-series variations of the other (environmental and biological) factors.

2.3. El Nino Southern Oscillation Index (SOI). The SOI which is an index of El Nino events as published by the Climate Research Unit was available at "http://www.cru.uea.ac.uk/" and was used to analyze the influence of the climate variability on the atmospheric conditions and water temperature in the study area. The relationships between environmental factors in the study area and the SOI were calculated using wavelet spectrum analysis [41, 42]. A fast Fourier transform (FFT) which is commonly used in time series analysis is an efficient algorithm to compute the discrete Fourier transform, but it requires that time series data 
TABLe 1: Instrument types in the World Ocean Database. (http://www.nodc.noaa.gov/OC5/WOD05/pr_wod05.html).

\begin{tabular}{ll}
\hline Datasets & Datasets include \\
\hline OSD & Ocean Station data, Low-resolution CTD/XCTD, Plankton data \\
CTD & CTD High-Resolution Conductivity-Temperature-Depth/XCTD data \\
MBT & Mechanical/Digital/Micro in the table Bathythermograph data \\
XBT & Expendable Bathythermograph data \\
SUR & Surface-only data \\
APB & Autonomous Pinniped Bathythermograph data \\
MRB & Moored buoy data \\
PFL & Profiling float data \\
DRB & Drifting buoy data \\
UOR & Undulating Oceanographic Recorder data \\
GLD & Glider data \\
\hline
\end{tabular}

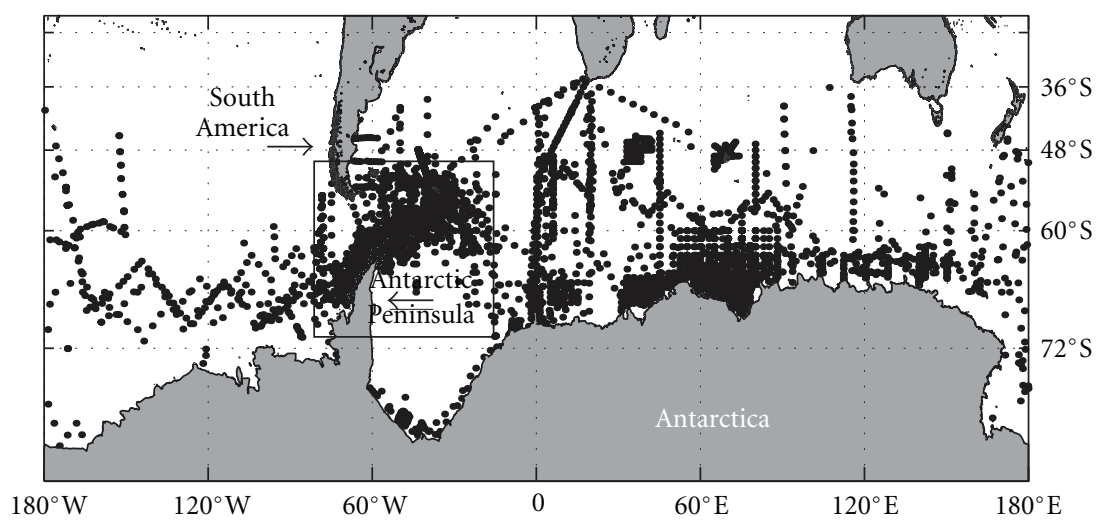

(a)

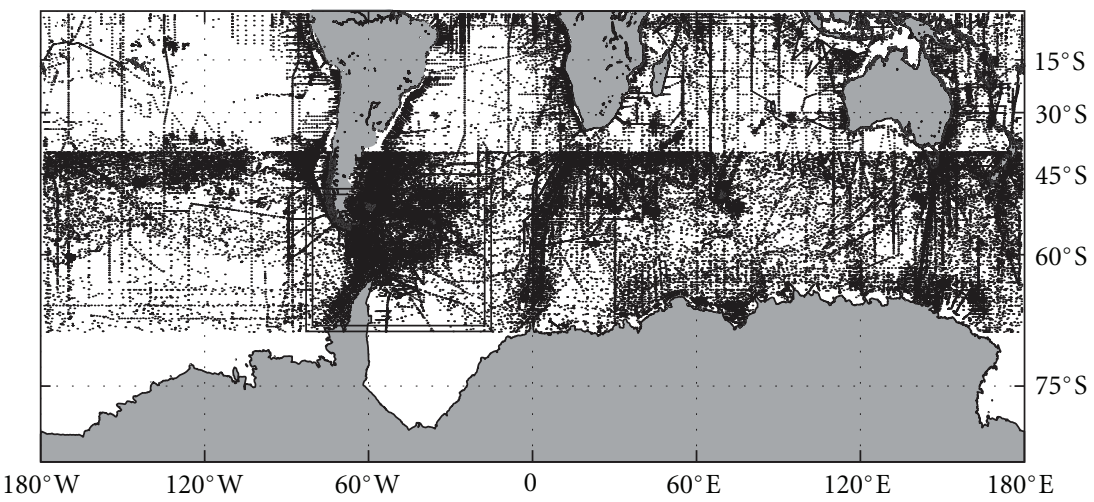

(b)

Figure 1: Sampling coverage for Antarctic krill and salps ((a), from [8]) from 1926 to 2002 and physical parameters from WOD01 and WOD05 from 1975 to 2002 (b) in the Southern Ocean. Rectangular boxes represent study area: 50-70 $\mathrm{S}$ and $20-80^{\circ} \mathrm{W}$.

are stationary. However, in case of wavelet spectrum, it is useful to analyze both stationary and nonstationary time series data. In this study, we used Morlet wavelet, which is useful to oceanic and atmospheric time series data that naturally have the sine-cosine fluctuation [43]. Further details of the Morlet wavelet used in this study are available at http://www.pol.ac.uk/home/research/waveletcoherence.

2.4. Chlorophyll-a. WOD01 and WOD05 data bases have included limited chlorophyll- $a$ (hereafter Chl $a$ ). Therefore, they were supplemented by the surface Chl $a$ data derived from CZCS, OCTS, and SeaWiFS (http://oceancolor.gsfc .nasa.gov/cgi/level3.pl.gsfc.nasa.gov/hcgi/level3.pl, level-3 standard mapped images (monthly composite images)). The image resolution was $9 \mathrm{~km} \times 9 \mathrm{~km}$. Each ocean color sensor was operated during different period. CZCS is available from October 1978 to June 1986 and OCTS-from November 1996 to June 1997, while SeaWiFS took over from September 1997. CZCS coverage is narrow relative to the other sensors, and its emphasis is on the coastal waters. Reprocessing 
TABLE 2: Mean abundance of Antarctic krill and salps in the study area averaged for January to March. Source: KRILLBASE [8]. N: number of stations.

\begin{tabular}{|c|c|c|c|c|}
\hline \multirow{2}{*}{ Field season } & \multicolumn{2}{|c|}{ Antarctic krill } & \multicolumn{2}{|c|}{ Salps } \\
\hline & $N$ & ind. $\mathrm{m}^{-2}$ & $N$ & ind. $\mathrm{m}^{-2}$ \\
\hline 1976 & 113 & 162.4 & 113 & 494.6 \\
\hline 1977 & - & - & - & - \\
\hline 1978 & 217 & 14.3 & 217 & 1.0 \\
\hline 1979 & - & - & - & - \\
\hline 1980 & 8 & 2.5 & - & - \\
\hline 1981 & 190 & 8.9 & 190 & 7.5 \\
\hline 1982 & 175 & 33.2 & 175 & 1.4 \\
\hline 1983 & - & - & - & - \\
\hline 1984 & 167 & 26.3 & 17 & 73.3 \\
\hline 1985 & 244 & 17.5 & 216 & 7.5 \\
\hline 1986 & - & - & - & - \\
\hline 1987 & - & - & - & - \\
\hline 1988 & 130 & 48.6 & - & - \\
\hline 1989 & 4 & 35.6 & 26 & 499.9 \\
\hline 1990 & 256 & 3.5 & 182 & 64.0 \\
\hline 1991 & 49 & 1.7 & 30 & 4.2 \\
\hline 1992 & 2 & 0 & 2 & 0 \\
\hline 1993 & 168 & 7.4 & - & - \\
\hline 1994 & 190 & 3.4 & 23 & 115.9 \\
\hline 1995 & 179 & 1.6 & 15 & 37.6 \\
\hline 1996 & 262 & 19.0 & 80 & 2.2 \\
\hline 1997 & 124 & 6.2 & 123 & 53.1 \\
\hline 1998 & 277 & 23.8 & 277 & 96.7 \\
\hline 1999 & 163 & 2.2 & 163 & 29.4 \\
\hline 2000 & 125 & 8.0 & 125 & 116.9 \\
\hline 2001 & 291 & 19.5 & 235 & 63.8 \\
\hline 2002 & 74 & 1.9 & 74 & 15.7 \\
\hline 2003 & 67 & 2.2 & 67 & 4.2 \\
\hline
\end{tabular}

of the Ocean color data collected by CZCS and OCTS sensors was completed in October 2006. Intercomparison of CZCS and SeaWIFS datasets using the global Chl $a$ data showed remarkable similarity between them. Chl $a$ retrievals are also in good agreement between OCTS and SeaWIFS but the former is biased low in the higher chlorophyll waters (http://oceancolor.gsfc.nasa.gov/). In this study, Chl a concentrations that were reprocessed in October 2006 (e.g., include CZCS, OCTS, SeaWiFS data sets) are used to compile the $\mathrm{Chl} a$ time series.

2.5. Antarctic Krill and Salp Densities. In addition to the KRILLBASE data (Table 2, http://www.iced.ac.uk/ science/krillbase.htm) $[8,9]$, published sources (Table 3) on krill and salp abundances around the Elephant Island were used in this study. Mean abundances of krill and salp presented in Table 1 were derived from the KRILLBASE over the entire area of observation (Figure 1). Stations with nontargeted oblique and vertical tows carried out during January-March were used for annual climatology calculations. Detailed information on the KRILLBASE
TABle 3: Mean abundance (ind.1000 $\mathrm{m}^{-3}$ ) of Antarctic krill and salps around the Elephant Island, Southern Ocean. Sources: [23, 44]. nd: no data.

\begin{tabular}{|c|c|c|}
\hline Field season & Antarctic krill & Salps \\
\hline 1975-76 & nd & 862 \\
\hline 1976-77 & nd & nd \\
\hline $1977-78$ & 133 & 4 \\
\hline 1978-79 & nd & nd \\
\hline 1979-80 & nd & nd \\
\hline $1980-81$ & 50 & 24 \\
\hline $1981-82$ & 511 & 25 \\
\hline $1982-83$ & 91 & nd \\
\hline $1983-84$ & 67 & 168 \\
\hline 1984-85 & 12 & 42 \\
\hline $1985-86$ & nd & 80 \\
\hline $1986-87$ & nd & nd \\
\hline $1987-88$ & 67 & 1 \\
\hline 1988-89 & 42 & 200 \\
\hline $1989-90$ & 15 & 3489 \\
\hline 1990-91 & 5 & nd \\
\hline 1991-92 & 25 & 94 \\
\hline $1992-93$ & 27 & 1400 \\
\hline 1993-94 & 29 & 714 \\
\hline 1994-95 & 9 & 18 \\
\hline 1995-96 & 95 & 26 \\
\hline $1996-97$ & 35 & 160 \\
\hline $1997-98$ & 78 & 675 \\
\hline 1998-99 & 13 & 173 \\
\hline $1999-2000$ & 11 & 415 \\
\hline 2000-01 & 22 & 278 \\
\hline 2001-02 & 98 & 245 \\
\hline 2002-03 & 84 & 41 \\
\hline 2003-04 & 32 & 79 \\
\hline 2004-05 & 18 & 491 \\
\hline 2005-06 & 13 & 24 \\
\hline
\end{tabular}

can be found in the electronic supplementary appendices of [8]. In addition, mean krill and salp densities were derived for the international AMLR (Antarctic Marine Living Resources Program) monitoring site around the Elephant Island situated close to the Antarctic Peninsula during December-March every year between 1975 and 2006 $[23,44]$.

\section{Results}

There are substantial differences in the T-S diagrams showing sea water properties from 1975 to 2002 (Figure 2). Temperatures and salinities in this diagram were averaged every 5 years from 1975 to 1999 and 3 years from 2000 to 2002. Several water masses with different characteristics were visible in the study area. These included Antarctic Bottom Water, North Atlantic Deep Water, Antarctic Intermediate Water, Circumpolar Deep Water, and Antarctic Circumpolar Water. Almost throughout the entire water column 

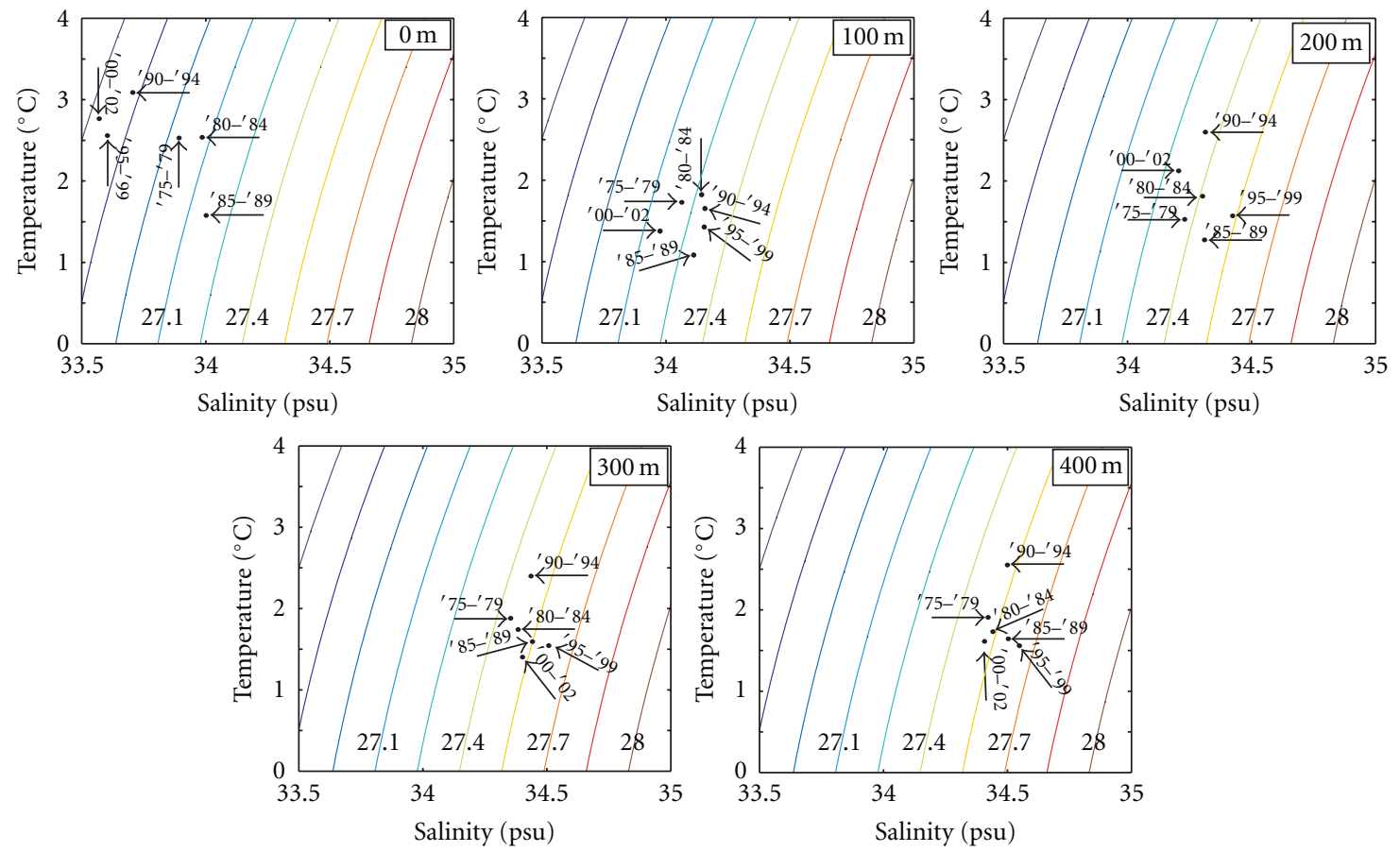

FIGURE 2: T-S diagrams at all depths during austral summer from 1975 to 2002. The data were averaged for 5-year periods: 1975-1979, 1980-1984, 1985-1989, 1990-1994, 1995-1999, 2000-2002 (only 3 years) for the period 1975-2002.

$60^{\circ} \mathrm{W} \quad 30^{\circ} \mathrm{W}$
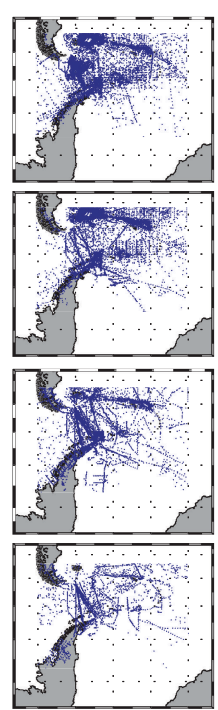

$60^{\circ} \mathrm{W} \quad 30^{\circ} \mathrm{W}$
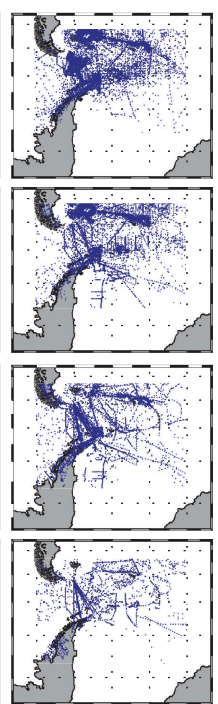

$60^{\circ} \mathrm{W} \quad 30^{\circ} \mathrm{W}$
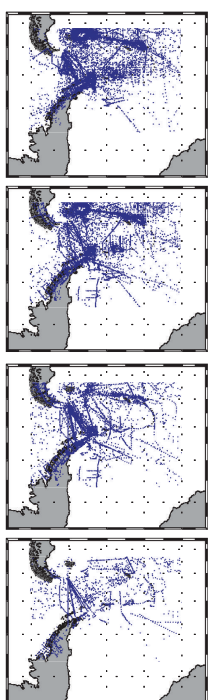

$60^{\circ} \mathrm{W} \quad 30^{\circ} \mathrm{W}$

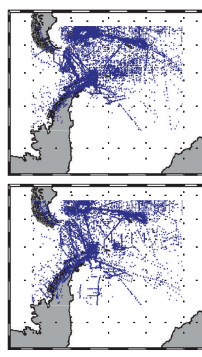

$60^{\circ} \mathrm{W} \quad 30^{\circ} \mathrm{W}$
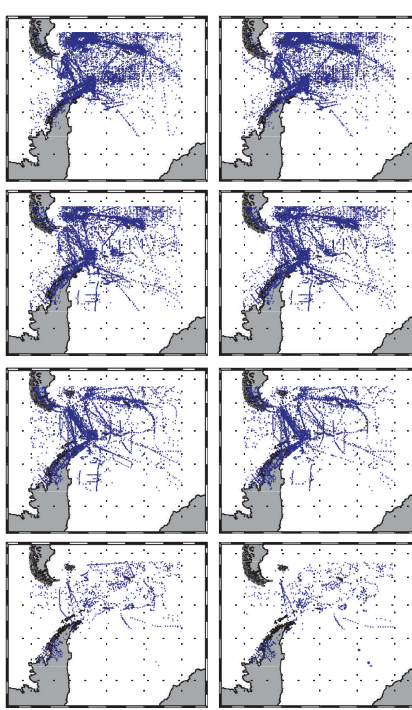

$60^{\circ} \mathrm{W} \quad 30^{\circ} \mathrm{W}$

$60^{\circ} \mathrm{W} \quad 30^{\circ} \mathrm{W}$
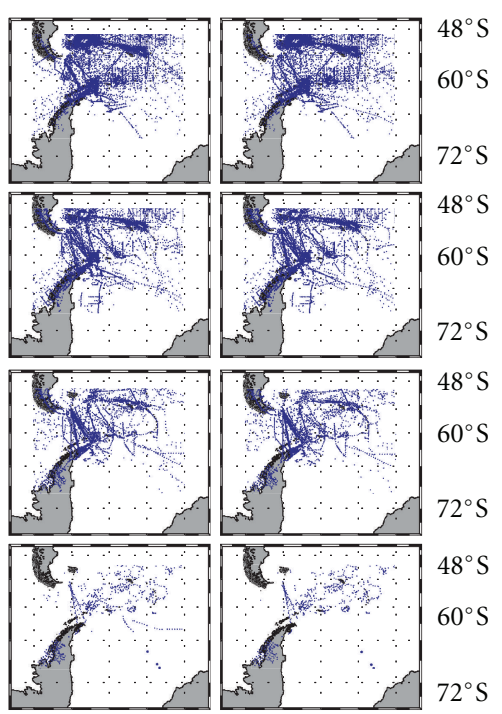

Figure 3: Stations used for T-S diagrams shown in Figure 2. Each panel presents January-March data for the period 1975-2002. These stations include measurements by various instruments shown in Table 1.

$(0-400 \mathrm{~m})$ temperatures and salinities ranged within the narrow interval, for example, from $1^{\circ}$ to $3^{\circ} \mathrm{C}$ and from 33.5 to 34.5 , respectively. Nevertheless, sea water at all depths became warmer and less saline during the period 1975 to 2002. This increasing trend was not monotonic, for example, sea water temperature decreased gradually after 1975-1979 till 1985-1989 then increased to 19901994 and decreased again until 1995-1999 showing only slight increase thereafter. The warming trends were similar at all sampling depths. Field observations were concentrated mainly around two regions, Antarctic Peninsula and South Georgia, although south-eastern part of the Weddell Sea was also covered (Figure 3 ). It was also comparable throughout the whole period of observations, and consequently the changes observed concern the region as a whole. 

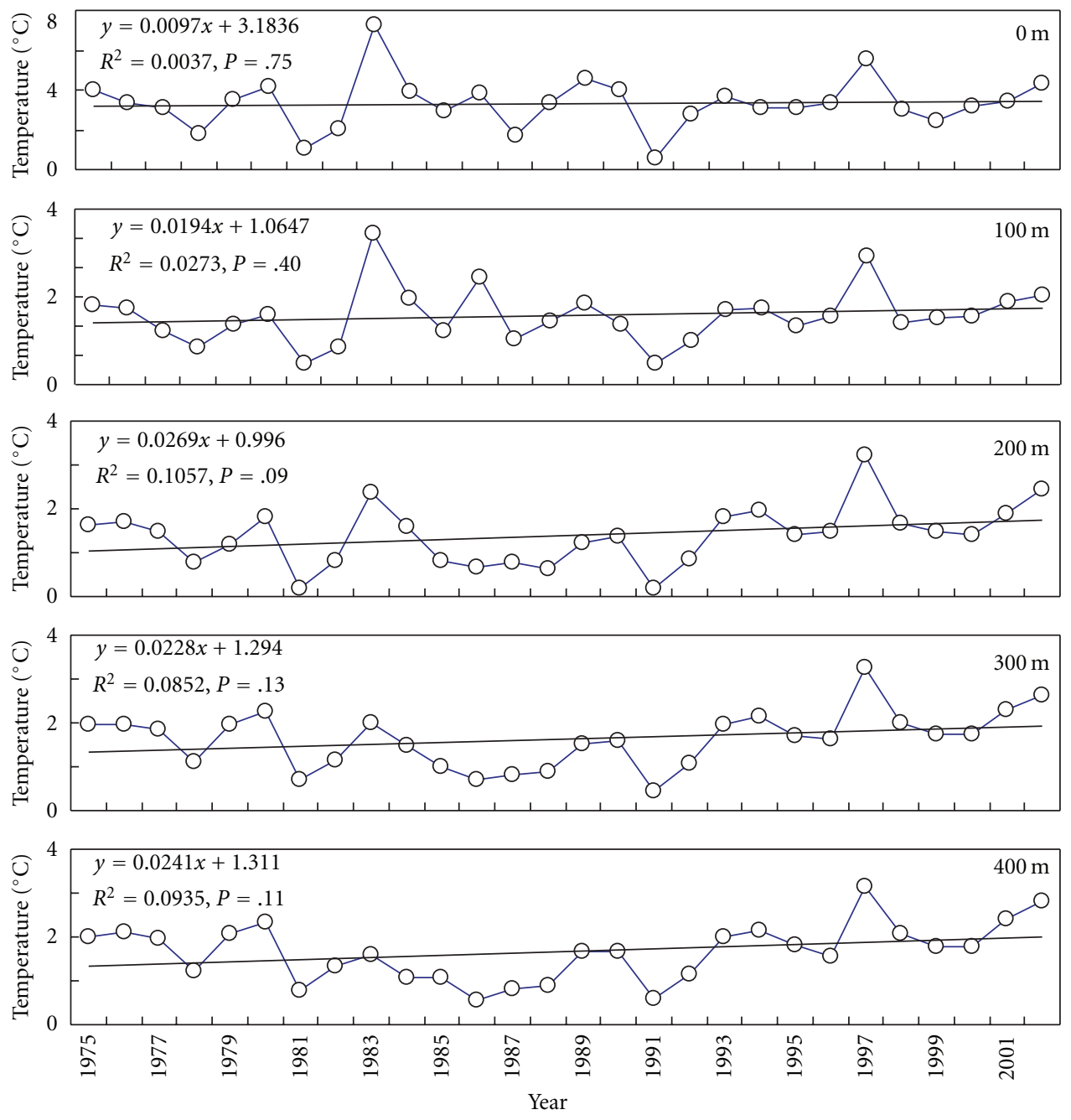

Figure 4: Long-term time series of the mean sea water temperature at the surface, $100 \mathrm{~m}, 200 \mathrm{~m}, 300 \mathrm{~m}$, and $400 \mathrm{~m}$ during austral summer (January-March) between 1975 and 2002. Solid lines represent linear regressions.

Temperature variability on the annual basis showed that between 1975 and 2002 there were several periods of sharp temperature changes. A particularly dramatic change in sea water temperature climatology occurred during 1980-1983, 1990-92, and 1996-98 (Figure 4). Annual mean temperature between surface and $400 \mathrm{~m}$ from 1975 to 2002 increased by $0.020^{\circ} \mathrm{C}-0.034^{\circ} \mathrm{C} \cdot \mathrm{yr}^{-1}$, and an increase in mean temperature was the lowerst $\left(0.020-0.028^{\circ} \mathrm{C} \cdot \mathrm{yr}^{-1}\right)$ at $200-400 \mathrm{~m}$ compared to the upper $0-100$ strata $\left(0.031-0.033^{\circ} \mathrm{C} \cdot \mathrm{yr}^{-1}\right)$ (Figure 4).

Vertical sections for every 5-year period from 1975 to 2002 have shown that overall temperature distribution was similar prior to 1985 and after 1990 (Figure 5). The period 1985-1989 appeared to be the coldest among all years of observation. Except this period, warm water spreads towards the Antarctic Peninsula, and its thickness deepens throughout the period of observation. In addition, the contour line of $1^{\circ} \mathrm{C}$ isotherm near the surface after the period 1985-1989 also retreats gradually towards the Antarctic
Peninsula confirming the warming trend observed earlier (Figure 5).

The variation in salinity showed a different pattern compared to temperature (Figure 6). Mean salinity at $0 \mathrm{~m}$ and $100 \mathrm{~m}$ decreased gradually at the rate of $0.005-0.012 \mathrm{yr}^{-1}$ from 1975 to 2002. However in the layers below $100 \mathrm{~m}$, salinity slightly increased at the rates $0.001-0.003 \mathrm{yr}^{-1}$ during the same period (Figure 6). Changes in salinity were greater in 1981-1982, 1991-1992, and 1997-1998 compared to the overall data set. Also, mean salinity from 1975-1979 to 20002002 except 1985-1989 and 2000-2002 increased between $200 \mathrm{~m}$ and $400 \mathrm{~m}$ strata (Figure 2).

Variation of dissolved oxygen concentrations followed negatively related pattern to the sea water temperatures. For example, in the higher temperature periods, dissolved oxygen showed lower concentrations, while the lower temperatures were associated with the elevated dissolved oxygen concentrations (Figures 4 and 7). Overall, the whole depth dissolved oxygen concentrations decreased 


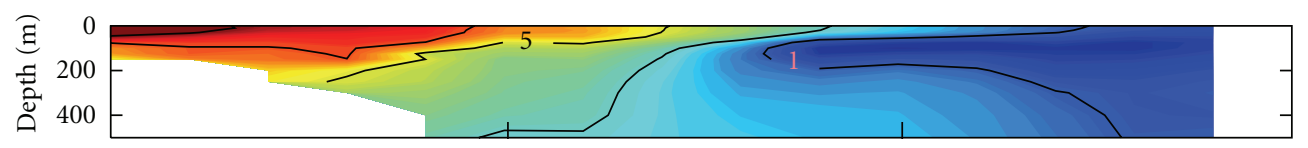

(a)

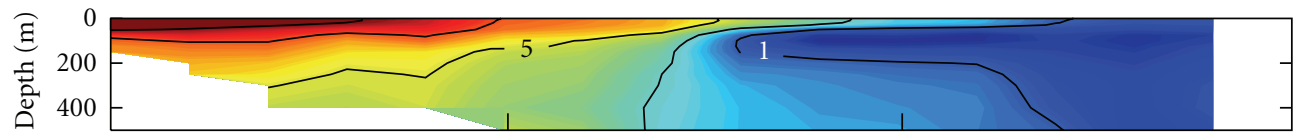

(b)

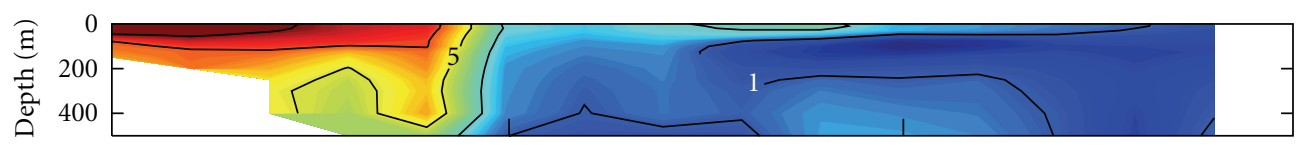

(c)

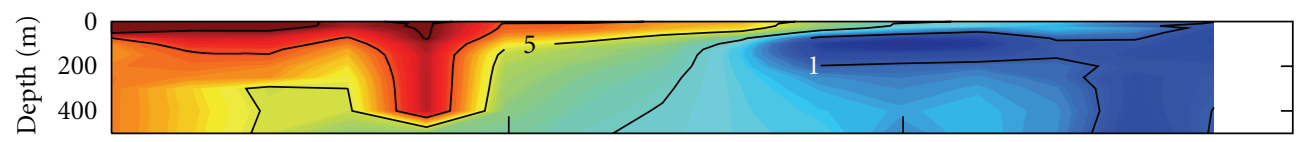

(d)

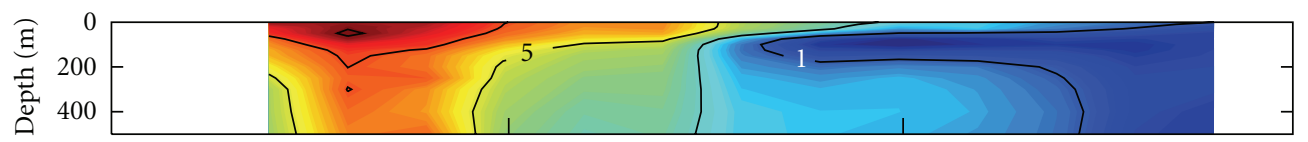

(e)

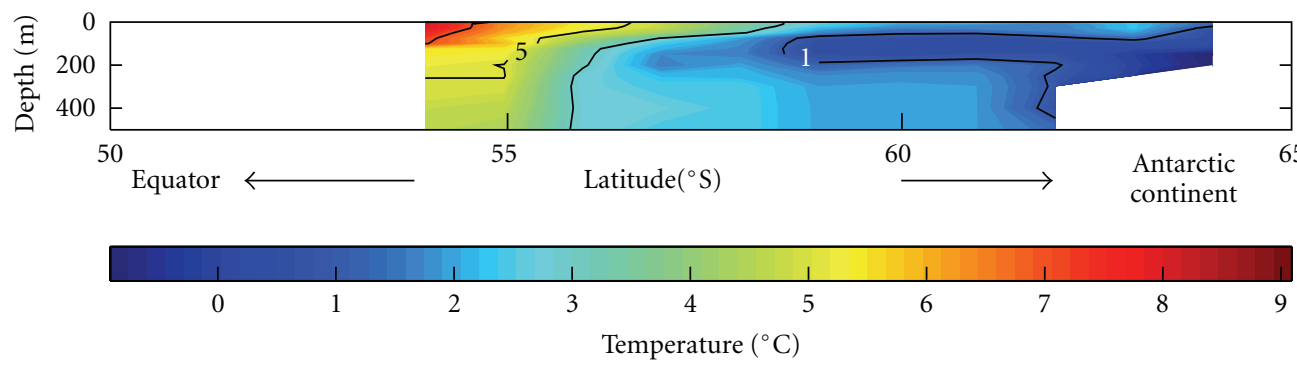

(f)

Figure 5: Vertical sections of the 5-year mean sea water temperature for the region $50^{\circ}-65^{\circ} \mathrm{S}$ and $59-65^{\circ} \mathrm{W}$ during austral summer (JanuaryMarch). (a) 1975-1979, (b) 1980-1984, (c) 1985-1989, (d) 1990-1994, (e) 1995-1999, and (f) 2000-2002.

gradually from 1975 to 2002 at an annual rate of $0.008-$ $0.033 \mathrm{~mL} \cdot \mathrm{L}^{-1}$ with the highest change rate at $200 \mathrm{~m}$ (Figure 7).

In the Southern Ocean, nutrient concentrations are always lowest at the surface layers and greatest in the Warm Deep Waters particularly for nitrates and phosphates, while silicates had the highest levels near $400 \mathrm{~m}$. Generally, nutrient concentrations decreased during the period 1975 to 2002 (Figures 8-10). Phosphate concentrations decreased at $0-200 \mathrm{~m}$ depths, while they increased slightly at 300$400 \mathrm{~m}$ depth strata. In early 1980s, phosphate concentrations showed dramatic change (Figure 8). Similarly to phosphates, nitrate concentrations decreased between 0-100 m and increased at 200-400 $\mathrm{m}$ (Figure 9). Unlike previous nutrients, silicate concentrations increased at $0 \mathrm{~m}$ and $200 \mathrm{~m}$ depth strata, while showed a decreasing trend at $100 \mathrm{~m}$, $300 \mathrm{~m}$, and $400 \mathrm{~m}$ (Figure 10).
Chl a concentrations extracted from WOD01 and WOD05 have been complemented with the SeaWiFS data (Figure 11). Although the SeaWiFS data between 1987 and 1996 were missing, both data sets showed a decreasing trend in Chl $a$ concentrations.

Sea-ice has an important role in Antarctic marine ecosystems. Sea-ice algae are known to be a critical food resource, boosting early adult spawning of krill in spring and survival of its larvae throughout winter, as well as possibly shielding krill from predation [23, 45]. Time series variations of sea-ice extent and air temperature are shown in Figure 12. Data on sea-ice extent used in this study represents its northernmost boundary. Variation in the sea-ice extent strongly negatively correlated with air temperature (Figure 12). Overall, although variable the sea ice extent decreased over the observed period (Figure 12). 

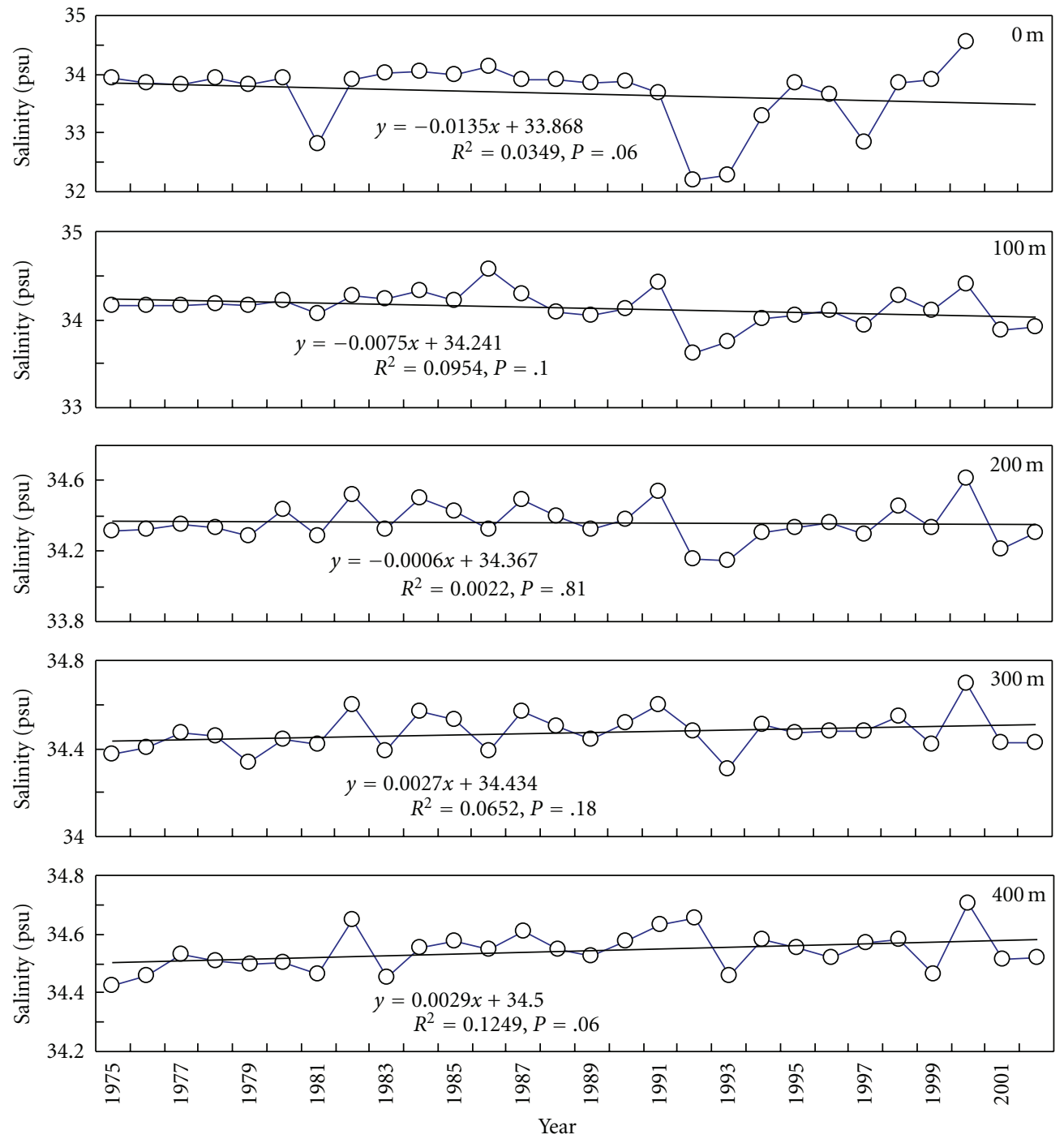

Figure 6: Long-term time series of the mean sea water salinity at the surface, $100 \mathrm{~m}, 200 \mathrm{~m}, 300 \mathrm{~m}$, and $400 \mathrm{~m}$ during austral summer (January-March) between 1975 and 2002. Solid lines represent linear regressions.

Generally, there was an inverse relationship between krill and salp densities (Tables 2 and 3). However, when plotted together it was negative from 1970s till the beginning of 1990s and then again after 2000s (Figure 13). Krill densities decreased over the study period but they were not monotonic with the lowest densities in mid-1990s. Salp densities increased till the beginning 1990s, when they stabilized. Although they were the highest during the early to mid 1990s, salp densities did not drop to the pre-1990s levels and in recent decade appeared to show periods of a prolonged dominance, for example, 1997-2002 (Figure 13). It should be noted that patterns of the mean abundances of both Antarctic krill and salps were similar between Elephant Island (regional) and Scotia Sea (basin scale) study regions (Figure 13). It is not entirely clear if this was a result of the overall similarity of processes at the basin scale or due to the fact that Elephant Island data set was large enough to drive the basin-scale pattern. The latter however is unlikely as the Antarctic Peninsula and the Weddell Sea regions were also readily sampled (Figure 3), and we suggest that the Elephant Island data set may reflect basin scale processes in the study area. There was a strong short-term variability in both krill and salp abundance in the study region. For example, krill densities around Elephant Island were relatively high in 1977-1978, 1981-1984, 1987-1988, 1995-1998 and 2001-2003, while salp densities peaked in 1975-1976, 1983-1984, 1988-1990, 1992-1994, 1997-2002, and 2004-05 (Table 3).

\section{Discussion}

The main aim of this study was to show interannual variability and longer-term trends in environmental parameters and Antarctic krill and salp populations in the South Atlantic sector of the Southern Ocean, the most significant habitat of the Antarctic krill, and look for the driving forces of this 

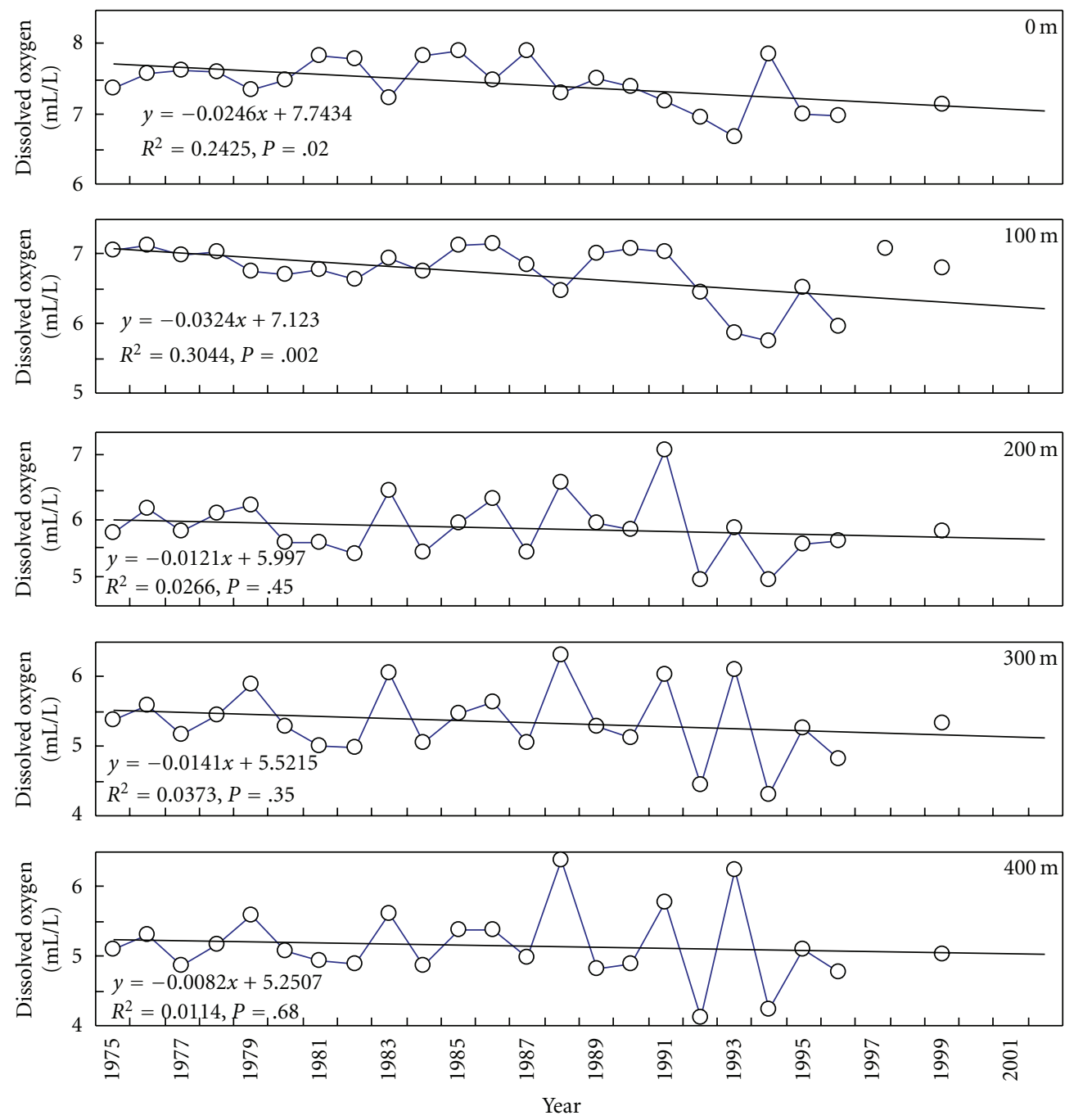

FIGURE 7: Long-term time series of the mean concentrations of the dissolved oxygen at the surface, $100 \mathrm{~m}, 200 \mathrm{~m}, 300 \mathrm{~m}$, and $400 \mathrm{~m}$ during austral summer (January-March) between 1975 and 2002. Solid lines represent linear regressions.

change. There were attempts of separating long-term trends from the short-term variability in the region investigated $[23,46,47]$. It has been noted that changes in krill and salp densities, as well as other zooplankton, occur rapidly $[46,47]$. Although, salps have one year life cycle [11] and capable to reflect sharp changes in an environment, Antarctic krill has much longer ( $>5$ years) life span, and sharp changes in its density would more likely be a result of the fundamental shifts in the habitat such as dramatic shift in the main frontal systems and replacing water masses with specific communities $[46,48]$. Our data show that such changes may be occurring at the basin scale pointing to the large scale "regime-like" shifts in the Southern Ocean [46]. The regime shift research in the Southern Ocean is, however, still rudimentary [46].

Up to now, several studies on marine environmental factors and density and distribution of mainly Antarctic krill have focused on relatively localized areas [23, 46, 47]. Statistically significant trends have been identified for sea water temperature and salinity. In this study, similar directional changes in marine environmental parameters were also identified but were mostly nonsignificant likely due to inherent enormous natural variability of parameters within the large area of investigation.

An increase rate of temperature calculated in this study was $0.02-0.034^{\circ} \mathrm{C} \cdot \mathrm{yr}^{-1}$. This was comparable or slightly higher than increase observed at west of Antarctic Peninsula, north of the Polar Front, and around South Georgia (range $\left.0.012-0.02^{\circ} \mathrm{C}\right)[17,49]$ but lower than warming of $\sim$ $0.05^{\circ} \mathrm{C} \cdot \mathrm{yr}^{-1}$ observed in the Weddell Sea between 1992 and 1998 [50]. According to the other studies, the mean warming of the Weddell Deep Water (WDW) was $\sim 0.032^{\circ} \mathrm{C}$ per decade that was comparable $\left(0.03-0.07^{\circ} \mathrm{C}\right.$ per decade $)$ to the warming around South Georgia, in the Antarctic Circumpolar Current and in the Southern Ocean overall [16$18,22,51,52]$. This clearly indicates that the basin scale environment of the study area warmed more intensively than other regions of the Southern Ocean. 

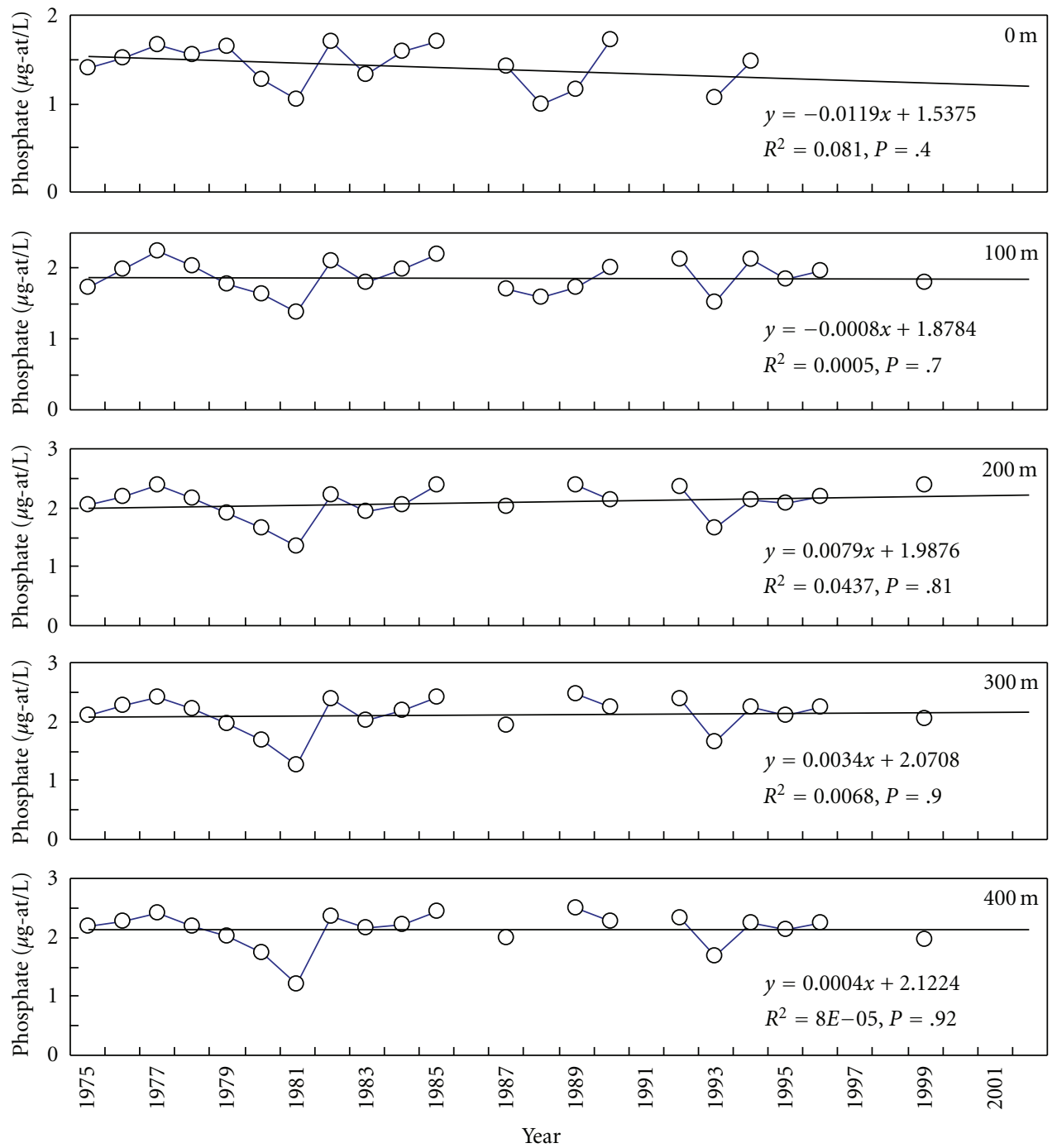

Figure 8: Long-term time series of the mean phosphate concentrations at the surface, $100 \mathrm{~m}, 200 \mathrm{~m}, 300 \mathrm{~m}$, and $400 \mathrm{~m}$ during austral summer (January-March) between 1975 and 2002. Solid lines represent linear regressions.

The spreading of warm water southwards and shrinkage of the cold water near the Antarctic Peninsula have been coupled with the long-term variations in salinity, dissolved oxygen, sea-ice extent, and air temperature (Figures 612). Overall, higher temperatures could have resulted in a decrease of the dissolved oxygen concentrations, while the shrinkage of the sea ice in the study region could have led to a less saline surface waters, both trends observed in this study. A change in the phytoplankton community structure by shifting it towards the smaller and/or nondiatom phytoplankton has been proposed by [3]. This would result in an increase of silica concentrations and decline in $\mathrm{Chl} a$ levels. Increased cloud cover and wind stress observed in recent decades in the northern Antarctic Peninsula region [53] may be further responsible for a decline in Chl $a$ concentrations. According to [3, 53, 54] above conditions would favor development of the salp populations and decrease in krill densities. Satellite-derived Chl $a$ concentrations confirmed that over the past 30 years along the western Antarctic
Peninsula surface summer pigment levels declined by $\sim 12 \%$, with the strongest decrease north of the $64^{\circ} \mathrm{S}$ and substantial increase further south [53].

Although we observed the trend-like changes in environmental parameters, there were several periods of abrupt changes/disturbances in the overall decreasing or increasing trends. It is impossible to assign these periods to regimeshift type changes, mostly due to absence of observations, but the studies in [46] suggested that such a regime shift might have occurred in the beginning of 1990s in the region adjacent to the Antarctic Peninsula and Elephant Island. Overall however, the short-term variability, particularly near the Antarctic Peninsula, was linked to ENSO events [5557] that thought to be related to the ecosystem-wide change [46]. Furthermore, long-term ALTR observations showed that prior to the mid1990s, during the period of the most abrupt change in sea-ice, there was a strong relationship between the sea ice extent and krill recruitment and biomass [23]. However, after the mid 1990s, when the sea-ice extent 

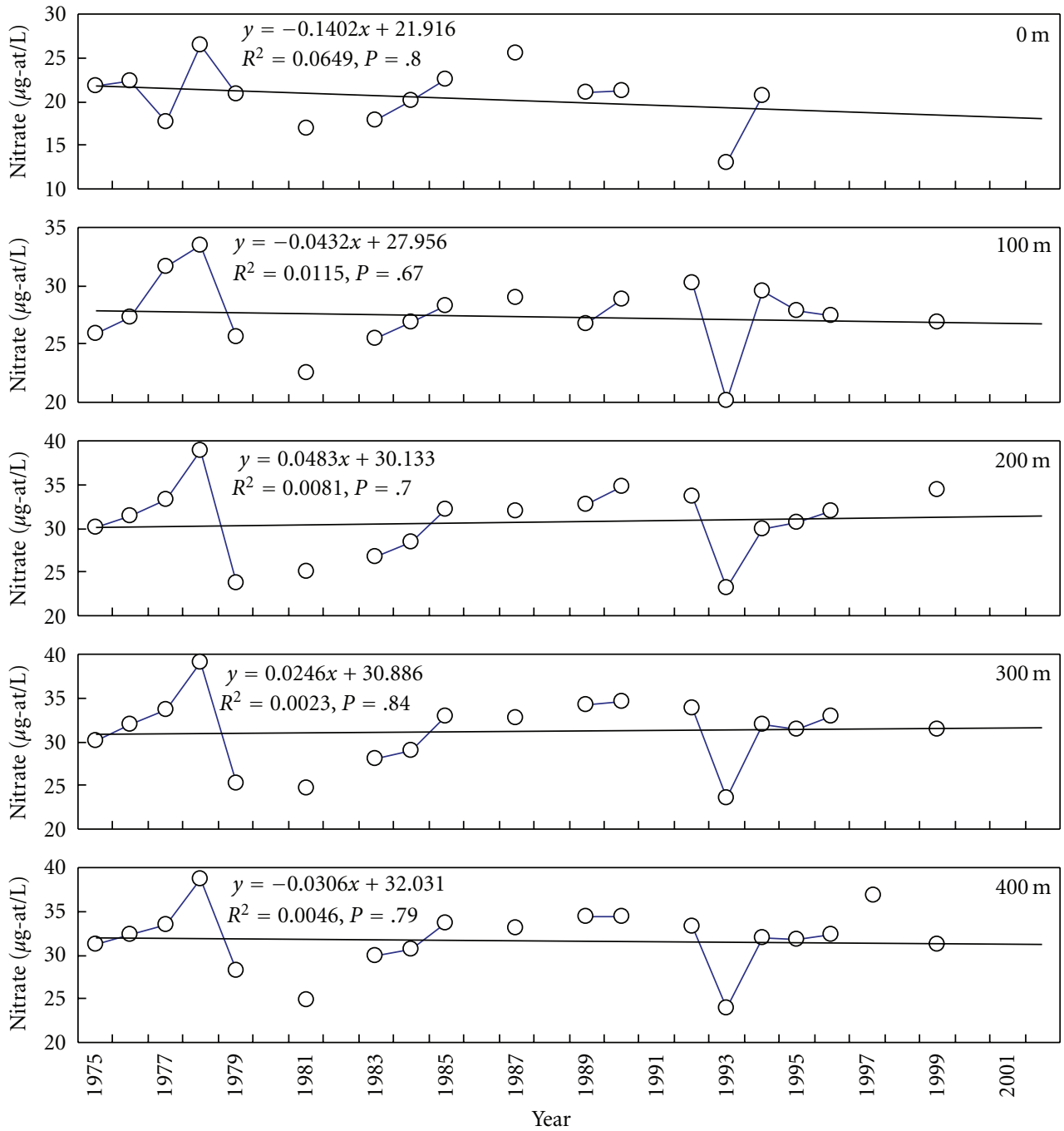

FIGURE 9: Long-term time series of the mean nitrate concentrations at the surface, $100 \mathrm{~m}, 200 \mathrm{~m}, 300 \mathrm{~m}$, and $400 \mathrm{~m}$ during austral summer (January-March) between 1975 and 2002. Solid lines represent linear regressions.

was relatively stable, densities of both krill and salps, while still fluctuating on a scale of 3-5 years, stabilized (Figure 13). In addition, inverse relationship between krill and salp dominating years observed prior mid 1990s has changed, and species often vary in the same phase. Mean krill and salp densities are now in the middle range, and salps showed extended periods of elevated densities. This may be indicative of the situation observed between the sharp ecosystem changes in the beginning of 1990s proposed by [46].

Regime shifts in the Northern Hemisphere have been well described [58-63]. For example, regime shifts in the North Pacific occurred in the late 1970s, 1980s, and possibly 1990s that were accompanied by a large-scale restructuring of the marine ecosystems. In this study, rapid changes in marine environmental factors occurred in the early 1980s, 1990s, and in the late of 1990s. If the Northern Hemisphere regime shifts could be linked to similar changes in the Southern Ocean, a teleconnection between hemispheres has a substantial lag in time and should be explained.
Recent modeling studies showed that there is a nonlinear relationship between the sea-ice extent and krill recruitment, and majority of the krill recruitment variability occurs within relatively narrow window of change in the sea-ice extent [64]. Thus, even relatively subtle sea-ice extent changes may affect dramatically the long-term variability in krill density suggesting that "regime-like" changes in krill and salp populations may occur. In the present study, however, it appears that the basin-scale change in the pelagic ecosystem physical setting may explain the long-term dynamics of krill and salp abundance in the Atlantic sector of the Southern Ocean.

In a parallel study, climatology indicated that krill and salps peak in abundance at species specific sets of the factors effectively showing that these metazoans inhabit different habitats in the Southern Ocean even in the regions where they mix together [65]. Finer scale studies seem to confirm the findings of the climatology analyses [31-33]. There is usually a time lag between oceanic conditions 

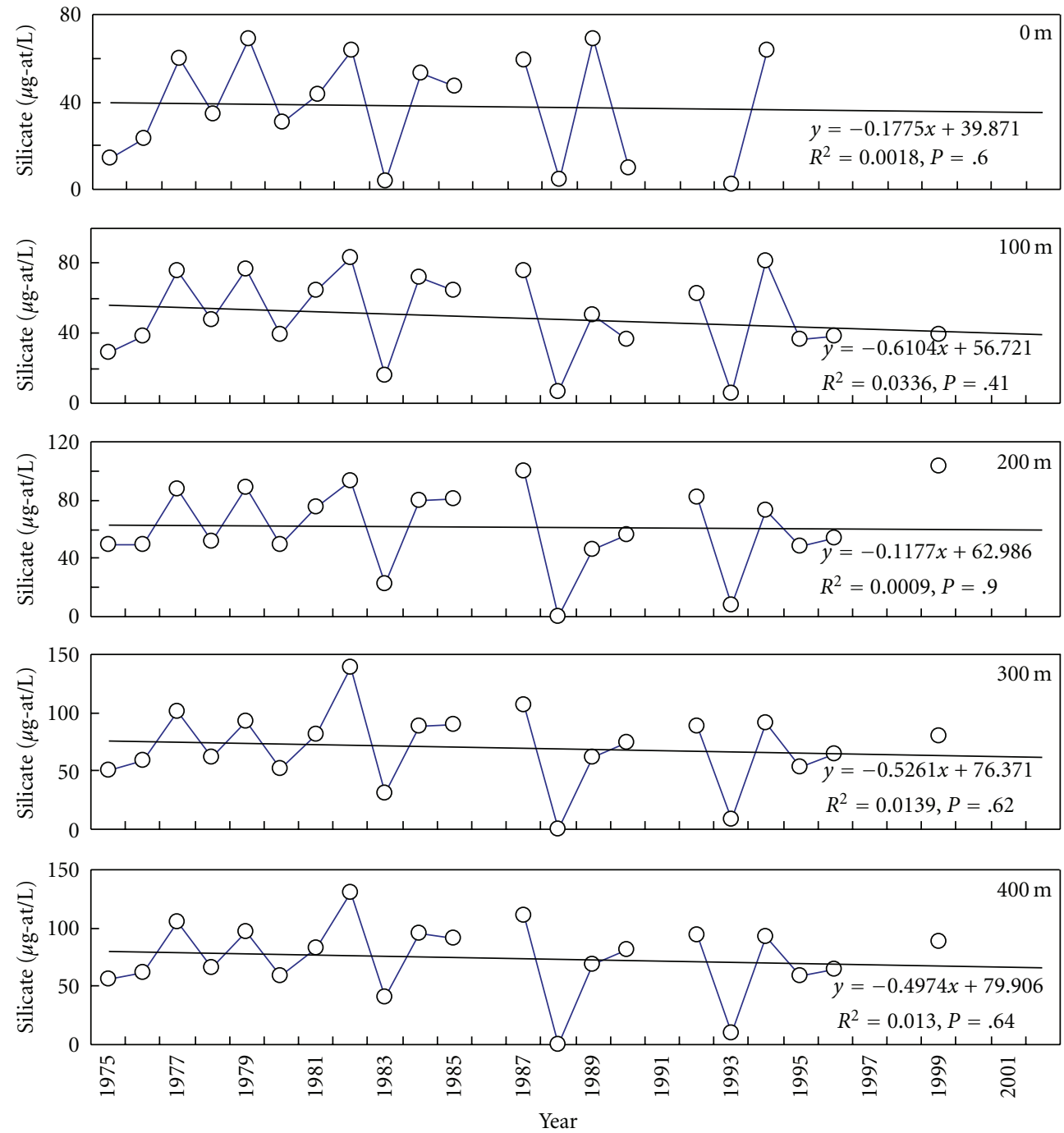

Figure 10: Long-term time series of the mean sea water silicate concentrations at the surface, $100 \mathrm{~m}, 200 \mathrm{~m}, 300 \mathrm{~m}$, and $400 \mathrm{~m}$ during austral summer (January-March) between 1975 and 2002. Solid lines represent linear regressions.

during the previous winter and the krill and salp abundance during the following summer $[23,46,66]$ suggesting that their stocks may follow long- and short-term variations in the marine environment. Unlike krill that has a life cycle of 5-7 years, salps live less than one year [11, 67]. Therefore, both long-term trends and short-term interannual variations in the marine environment should be more visible in the salp population. However, both krill and salps showed pronounced short term variability $[8,16,46]$ that is hard to explain by differences in their life spans. Alternatively, this might be linked to the ENSO cycles $[46,68]$ or in the case of krill to the strong recruitment events that also coincide with the ENSO events $[8,9,46,69]$. We showed the dramatic change of marine environment factors in the early of 1980s, 1990s, and in the late of 1990s, and changes in the sea water temperature were particularly prominent. Although several studies on regime shifts have been carried out, the mechanisms determining the breaking out of a regime shift are not yet clear. Therefore, an understanding of the mechanism triggering regime shifts is required to understand the variation in marine ecosystems.

What is the driving force for the warming trend around the Southern Ocean? According to previous studies [7072], an activity of Antarctic Circumpolar Wave (ACW) that propagates eastward with the circumpolar flow with a period of 4-5 years has been linked to the ENSO cycles. The ACW encircles the Antarctic continent within 8-10 years time window. In this study, El Nino activity (SOI index) and water temperature at surface and $100 \mathrm{~m}$ show the repeated periodicity of 2-8 years, particularly 3-5 years, throughout the whole period from 1960 to 2002 (Figure 14). There were periods of a rapid change approximately once a decade, for example, in 1966/67, 1976/77, 1987/88, and 1997/98, and some of these periods coincide with the regime shifts recorded in the Northern Hemisphere. The cross/coherency spectrum between SOI and the water temperature at surface and $100 \mathrm{~m}$ in the Atlantic sector of the Southern Ocean 

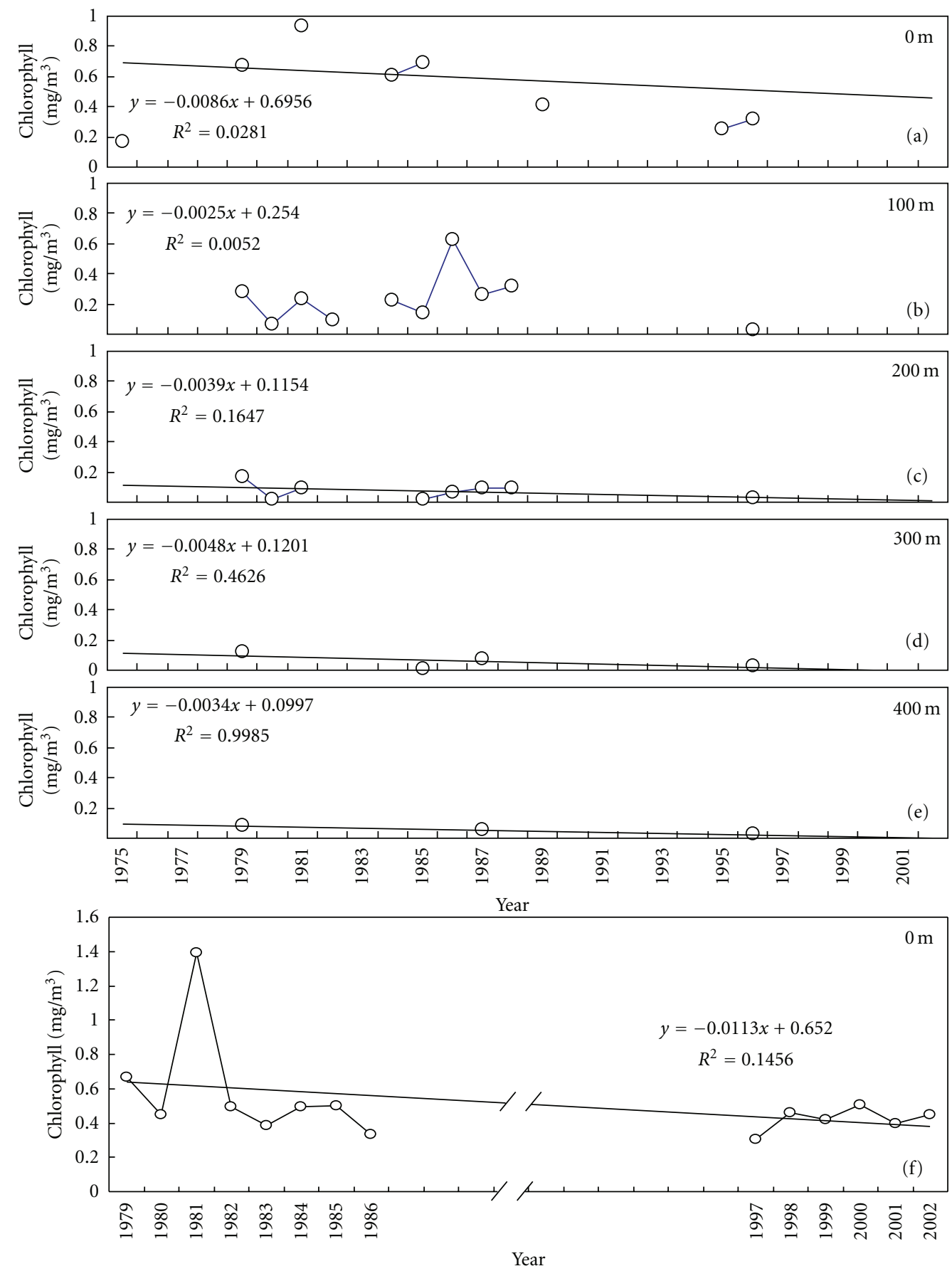

FIGURE 11: Long-term time series of Chl $a$ concentrations during austral summer (January-March) between 1975 and 2002; (a)-(e) WOD01 and WOD05 data; (f) SeaWiFS. Solid lines represent linear regressions.

suggested that they may be closely connected to each other (Figure 15). Water temperatures at the surface and $100 \mathrm{~m}$ depth have had the highest correlation with the SOI in the period of 4-6 years. It means that ACW and ENSO event interact with each other. This interaction could be explained from feedbacks between the ACW and ENSO cycle. There are positive feedbacks between the ACW and the ENSO [55], and these feedbacks are proceeded by atmospheric and oceanic teleconnections linking the ACW and ENSO [70]. The ENSO event is related to the eastward propagation of the SST and SLP anomalies across warm pool in the tropics. It forces remotely the ACW in the eastern Pacific and western Atlantic sectors of the Southern Ocean through the fast atmospheric teleconnections [73]. On the other hand, the ACW is found to force the ENSO event by a teleconnection from the high southern latitudes 


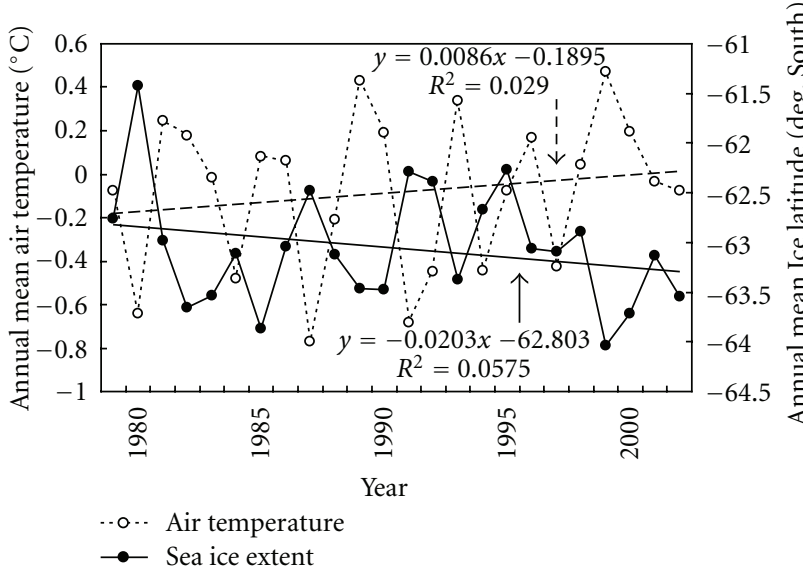

(a)

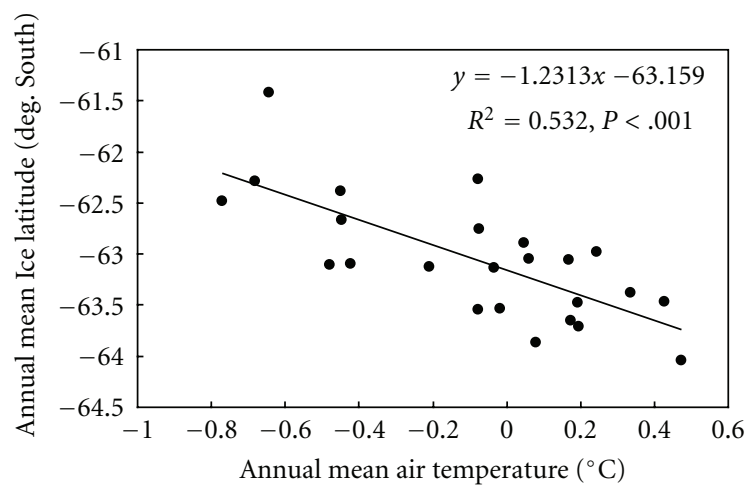

(b)

FIGURE 12: Time series of the annual mean air temperature and annual mean sea ice extent (a) and a linear correlation between two time series (b). Air temperature data were from South Georgia, and sea-ice extent was averaged for the region from 20 to $80^{\circ} \mathrm{W}$.

to the tropics via the ocean, and it is a relatively slow process [55]. According to [74], the ACW has a periodicity similar to the ENSO cycle. In our study, we also found a similar pattern between both events as described above. An interaction between the ACW and ENSO with similar periods may be related to a change of the mean global climate. It is thus possible to suggest that in the Southern Ocean, the only oceanic domain encircling the globe and where the Antarctic Circumpolar Current (ACC) is propagating eastward, the ACC is the unifying link for exchanges of water masses at all depthes between the world's major ocean basins [70]. Studies in [70] suggested that the Southern Ocean is expected to play an important role in transmitting climate anomalies around the globe because these exchanges are important in controlling the global climate. If we consider the feedbacks between the ACW and ENSO, interactions between both events are considered to be one of factors causing warming trend in the study area. According to [75], evolvement patterns of El Niño are different before and after 1977, and the change in the patterns was accompanied by the ACW's expansion and

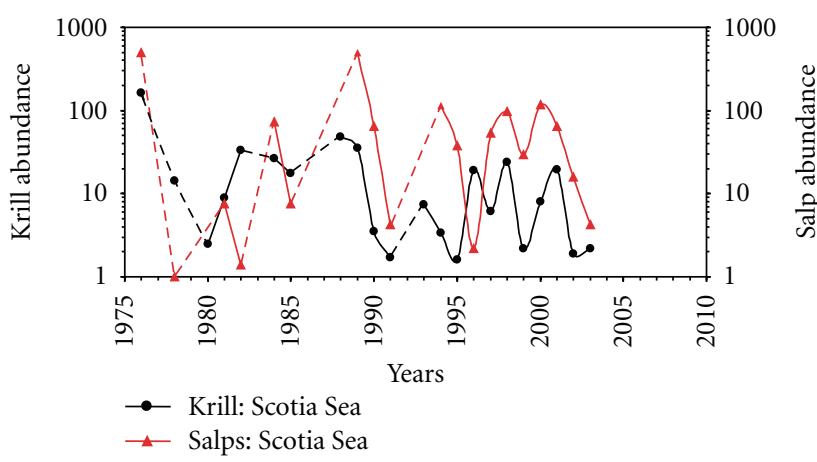

(a)

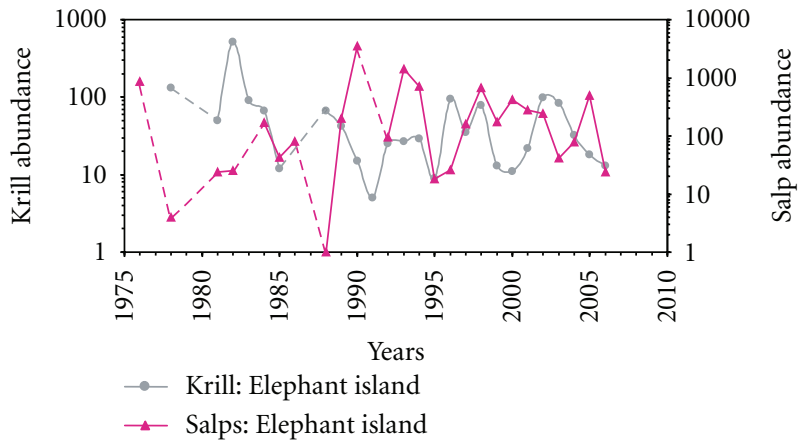

(b)

FIGURE 13: Long-term variability of Antarctic krill and salp densities (ind. $\mathrm{m}^{-2}$ in the Scotia Sea (a) and ind.1000 $0^{-3}$ around Elephant Island (b)) in the Atlantic sector of the Southern Ocean.

recession in the Indian and Pacific sectors of the Antarctic Ocean. It thus appears that the influence of the ACW on El Niño through these sectors may be related to global warming.

Time-longitude diagrams of anomalies in sea-ice extent show clear patterns of dominating eastward anomaly propagation (Figure 16). According to [75], the ACW appeared to be the strongest in the Pacific sector of the Southern Ocean and the weakest in the Indian sector. The ACWrelated anomalies progress eastward at an average speed of 6-8 $\mathrm{cm} \cdot \mathrm{s}^{-1}$, taking $8-10$ years for individual phases to travel around the Antarctic continent [76]. In our study, although particular phases are sometimes interrupted between $50^{\circ} \mathrm{E}$ and $100^{\circ} \mathrm{E}$, for example, in 1989 and 1990 , it takes $\sim 7-9$ years for sea-ice anomalies to travel around the Antarctic continent. Eastward propagation of sea-ice extent anomalies around the Antarctic continent repeated every 4-5 years (Figure 16). It should be noted that there was a strong eastward anomaly between $150^{\circ}$ and $50^{\circ} \mathrm{E}$ that persisted from 1985 to 1989 , from 1989 to 1994 , and 1995 to 1999 (Figure 16). These periods match well the intense of the El Nino events shown in Figure 14. The eastward movement in sea ice anomalies is associated with the extraordinary ice retreat toward the Antarctic continent [77]. It is apparent that these local fluctuations in sea ice were manifestations of propagating anomalies that can be traced back to the Indian Ocean some 5 years earlier. 


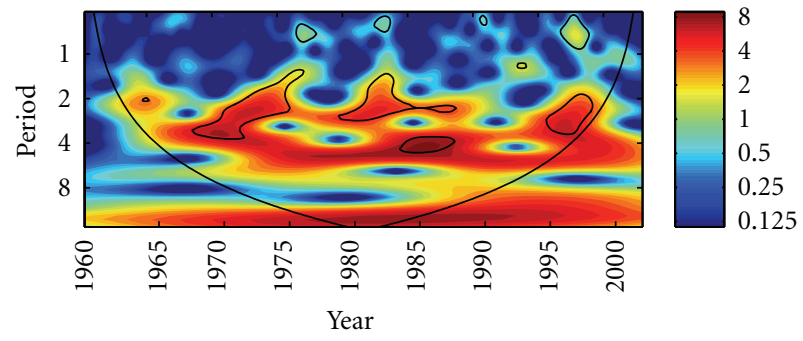

(a)

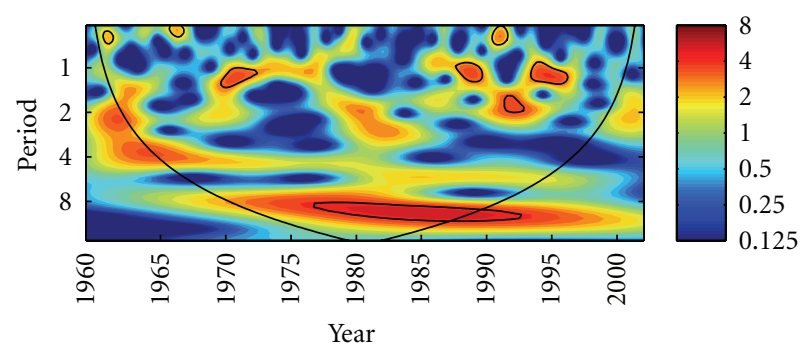

(b)

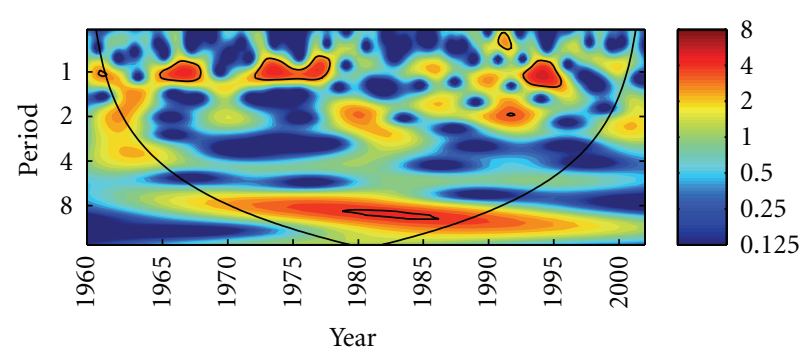

(c)

FIGURE 14: The wavelet autospectrum of SOI (a), water temperature at $0 \mathrm{~m}(\mathrm{~b})$, at $100 \mathrm{~m}(\mathrm{c})$. The $5 \%$ significance level against red noise is shown as a tick contour, and the thin black line indicates the cone of the influence.

In summary, it appears that all environmental factors, krill and salp densities in the Atlantic sector of Southern Ocean showed trend-like change during the long-term period. At this point, it is perhaps impossible to demonstrate the significance in relationships between environmental factors and krill and salps within this large area. Based on the long-term trends, it is, however, possible to hypothesize that both krill and salp densities could be linked to change in marine environmental factors such as sea water temperature, salinity, dissolved oxygen, nutrients, seaice extent, and air temperature. Recent studies showed that the warming trend of the Southern Ocean could largely be explained by the poleward migration of the ACC although other mechanisms, for example, increased heat flux from the atmosphere or increased poleward eddy heat flux should not be discounted [18]. Such displacement could bring anomalously warm waters into the contact even with the ice shelves and increase their melting [78-80]. In a short term, krill and salp populations as well as marine environment factors are strongly influenced by the interaction between $\mathrm{El}$ Nino (SOI) and the ACW.

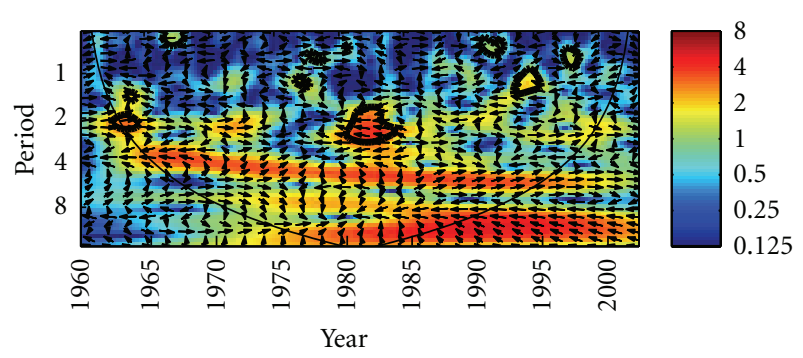

(a)

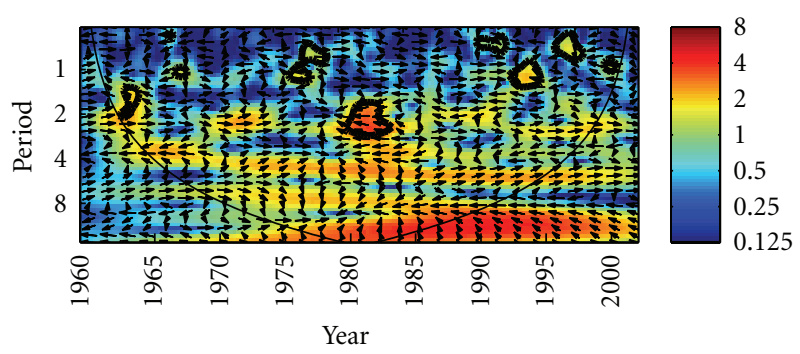

(b)

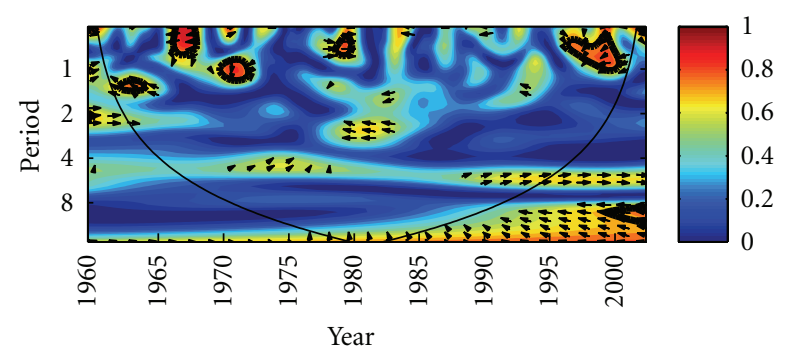

(c)

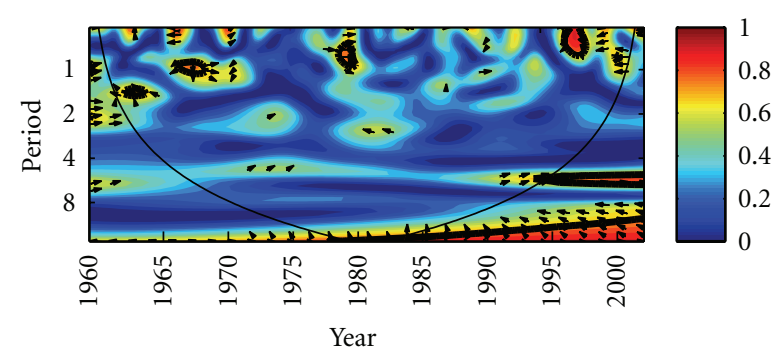

(d)

Figure 15: The wavelet cross-spectrum ( $a, b)$ and coherency spectrum $(c, d)$ between the SOI and water temperature at $0 \mathrm{~m}$ and $100 \mathrm{~m}$. The vectors indicate the phase difference between the SOI and water temperature (with in-phase pointing right, antiphase pointing left, an arrow pointing vertically means the second time series lags the first by $90^{\circ}$, that is, the phase angle is $270^{\circ}$. The $5 \%$ significance level against red noise is shown as a tick contour, and the thin black line indicates the cone of the influence.

\section{Acknowledgments}

This paper was supported by the National Research Foundation of Korea (NRF) funded by the Ministry of Education, Science and Technology (2010-0004617). The authors thank the Department of Earth and Ocean Sciences, University of 


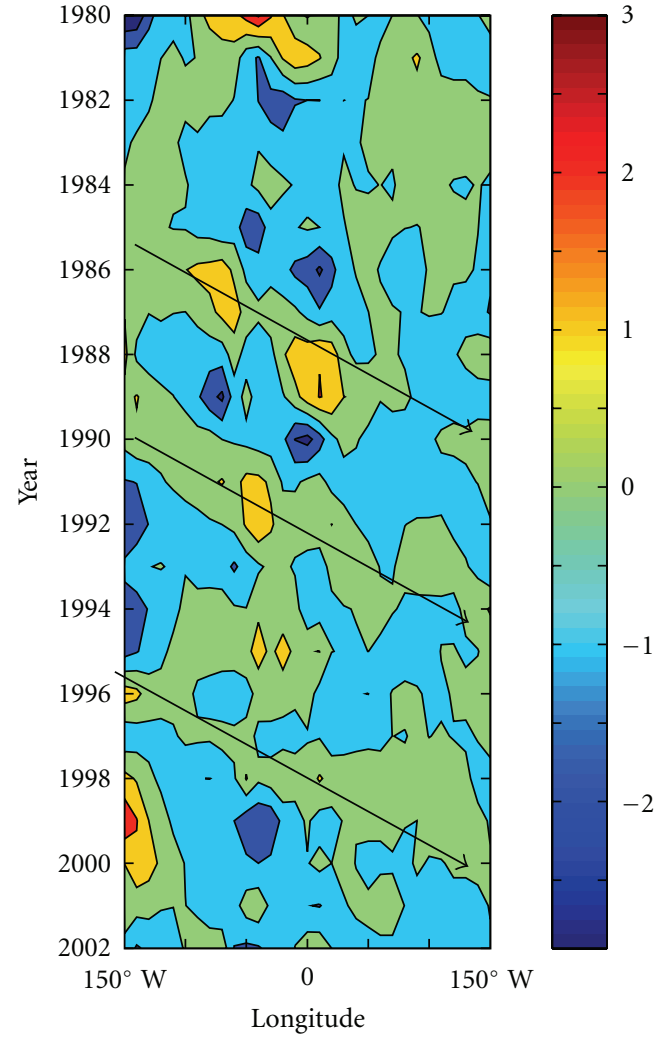

Figure 16: Time-longitude diagrams of inter-annual anomalies of the sea-ice extent during 1980 to 2002. Sea-ice extent data were averaged every $10^{\circ}$ longitude. Arrows indicate the propagation of Antarctic Circumpolar Wave inferred from the inter-annual anomalies.

British Columbia, Vancouver, Canada for accommodating Dr. C. Lee during his postdoctoral study.

\section{References}

[1] N. M. Voronina, Pelagic Ecosystems of the Southern Ocean, Nauka Press, Moscow, Russia, 1994.

[2] S. Kawaguchi and S. Nicol, "Learning about Antarctic krill from the fishery," Antarctic Science, vol. 19, no. 2, pp. 219-230, 2007.

[3] L. Fortier, J. Le Fevre, and L. Legendre, "Export of biogenic carbon to fish and to the deep ocean: the role of large planktonic microphages," Journal of Plankton Research, vol. 16, no. 7, pp. 809-839, 1994.

[4] M. A. Moline, H. Claustre, T. K. Frazer, J. Grzymski, O. Schofield, and M. Vernet, "Changes in phytoplankton assemblages along the Antarctic Peninsula and potential implications for the Antarctic food web," in Antarctic Ecosystems, Models for Wider Ecological Understanding, W. Davison, C. Howard-Williams, and P. Broady, Eds., pp. 263-271, The Caxon Press, Christchurch, New Zealand, 2000.

[5] J. M. Gili, S. Rossi, F. Pagès et al., "A new trophic link between the pelagic and benthic systems on the Antarctic shelf," Marine Ecology Progress Series, vol. 322, pp. 43-49, 2006.
[6] E. A. Pakhomov, P. W. Froneman, and R. Perissinotto, "Salp/krill interactions in the Southern Ocean: spatial segregation and implications for the carbon flux," Deep-Sea Research Part II, vol. 49, no. 9-10, pp. 1881-1907, 2002.

[7] J. W. S. Marr, "The natural history and geography of the Antarctic krill (Euphausia superba Dana)," Discovery Reports, vol. 32, pp. 33-464, 1962.

[8] A. Atkinson, V. Siegel, E. Pakhomov, and P. Rothery, "Longterm decline in krill stock and increase in salps within the Southern Ocean," Nature, vol. 432, no. 7013, pp. 100-103, 2004.

[9] A. Atkinson, V. Siegel, E. A. Pakhomov et al., "Oceanic circumpolar habitats of Antarctic krill," Marine Ecology Progress Series, vol. 362, pp. 1-23, 2008.

[10] A. Kawamura, "Has marine Antarctic ecosystem changed? A tentative comparison of present and past macrozooplankton abundances," Memoirs-National Institute of Polar Research, vol. 40, pp. 197-211, 1986.

[11] P. Foxton, "The distribution and life history of Salpa thompsoni Foxton with observations on a related species S.gerlachei Foxton," Discovery Reports, vol. 34, pp. 1-116, 1966.

[12] V. Siegel, A. Skibowski, and U. Harm, "Community structure of the epipelagic zooplankton community under the sea-ice of the northern Weddell Sea," Polar Biology, vol. 12, no. 1, pp. 15-24, 1992.

[13] S. Nicol, T. Pauly, N. L. Bindoff et al., "Ocean circulation off east Antarctica affects ecosystem structure and sea-ice extent," Nature, vol. 406, no. 6795, pp. 504-507, 2000.

[14] H. J. Zwally, "Breakup of Antarctic ice," Nature, vol. 350, no. 6316, p. 274, 1991.

[15] H. Rott, P. Skvarca, and T. Nagler, "Rapid collapse of northern Larsen Ice Shelf, Antarctica,” Science, vol. 271, no. 5250, pp. 788-792, 1996.

[16] M. J. Whitehouse, M. P. Meredith, P. Rothery, A. Atkinson, P. Ward, and R. E. Korb, "Rapid warming of the ocean around South Georgia, Southern Ocean, during the 20th century: forcings, characteristics and implications for lower trophic levels," Deep-Sea Research Part I, vol. 55, no. 10, pp. 12181228, 2008.

[17] S. Levitus, J. Antonov, and T. Boyer, "Warming of the world ocean, 1955-2003," Geophysical Research Letters, vol. 32, no. 2 , Article ID L02604, 4 pages, 2005.

[18] S. T. Gille, "Decadal-scale temperature trends in the Southern Hemisphere ocean," Journal of Climate, vol. 21, no. 18, pp. 4749-4765, 2008.

[19] M. A. J. Curran, T. D. van Ommen, V. I. Morgan, K. L. Phillips, and A. S. Palmer, "Ice core evidence for Antarctic sea ice decline since the 1950s," Science, vol. 302, no. 5648, pp. 12031206, 2003.

[20] C. Cotté and C. Guinet, "Historical whaling records reveal major regional retreat of Antarctic sea ice," Deep-Sea Research Part I, vol. 54, no. 2, pp. 243-252, 2007.

[21] S. E. Stammerjohn, D. G. Martinson, R. C. Smith, X. Yuan, and D. Rind, "Trends in Antarctic annual sea ice retreat and advance and their relation to El Niño-Southern Oscillation and Southern Annular Mode variability," Journal of Geophysical Research C: Oceans, vol. 113, no. 3, Article ID C03S90, 2008.

[22] S. Levitus, J. I. Antonov, T. P. Boyer, and C. Stephens, "Warming of the world ocean," Science, vol. 287, no. 5461, pp. 2225-2229, 2000.

[23] V. Loeb, V. Siegel, O. Holm-Hansen et al., "Effects of sea-ice extent and krill or salp dominance on the Antarctic food web," Nature, vol. 387, no. 6636, pp. 897-900, 1997. 
[24] D. Ainley, G. Ballard, S. Ackley et al., "Paradigm lost, or is topdown forcing no longer significant in the Antarctic marine ecosystem?" Antarctic Science, vol. 19, no. 3, pp. 283-290, 2007.

[25] S. Nicol, J. Croxall, P. Trathan, N. Gales, and E. Murphy, "Paradigm misplaced? Antarctic marine ecosystems are affected by climate change as well as biological processes and harvesting," Antarctic Science, vol. 19, no. 3, pp. 291-295, 2007.

[26] S. Chiba, T. Ishimaru, G. W. Hosie, and S. W. Wright, "Population structure change of Salpa thompsoni from austral mid-summer to autumn," Polar Biology, vol. 22, no. 5, pp. 341$349,1999$.

[27] L. B. Quetin, R. M. Ross, and A. Clarke, "Krill energetics: seasonal and environmental aspects of the physiology of Euphausia superb," in Southern Ocean Ecology, The Biomass Perspective, S. Z. El-Sayed, Ed., pp. 165-184, Cambridge University Press, Cambridge, UK, 1994.

[28] S. Kawaguchi and Y. Takahashi, "Antarctic krill (Euphausia superba dana) eat salps," Polar Biology, vol. 16, no. 7, pp. 479$481,1996$.

[29] H. G. Fransz and S. R. Gonzalez, "Latitudinal metazoan plankton zones in the Antarctic Circumpolar Current along $6^{\circ} \mathrm{W}$ during austral spring 1992," Deep-Sea Research Part II, vol. 44, no. 1-2, pp. 395-414, 1997.

[30] E. A. Pakhomov, "Salp/krill interactions in the eastern Atlantic sector of the Southern Ocean," Deep-Sea Research Part II, vol. 51, no. 22-24, pp. 2645-2660, 2004.

[31] E. A. Pakhomov, "Vertical distribution and diel migrations of Antarctic macroplankton," in Pelagic Ecosystems of the Southern Ocean, N. M. Voronia, Ed., pp. 146-150, Nauka Press, Moscow, Russia, 1993.

[32] E. A. Pakhomov, "Diel vertical migrations of Antarctic macroplankton. Salpidae, Ctenophora, Coelenterata, Chaetognatha, Polychaeta, Pteropoda," Oceanology, vol. 33, pp. 510-511, 1994.

[33] I. A. Catalán, B. Morales-Nin, J. B. Company, G. Rotllant, I. Palomera, and M. Emelianov, "Environmental influences on zooplankton and micronekton distribution in the Bransfield Strait and adjacent waters," Polar Biology, vol. 31, no. 6, pp. 691-707, 2008.

[34] D. L. Rudnick, R. E. Davis, C. C. Eriksen, D. M. Fratantoni, and M. J. Perry, "Underwater gliders for ocean research," Marine Technology Society Journal, vol. 38, no. 2, pp. 73-84, 2004.

[35] T. P. Boyer, J. I. Atonov, H. E. Garcia et al., "World ocean database 2005," in NOAA Atlas NESDIS 60, S. Levitus, Ed., p. 190, DVDs, U.S. Government Printing Office, Washington, DC, USA, 2006.

[36] P. Gloersen and W. J. Campbell, "Recent variations in arctic and Antarctic sea-ice covers," Nature, vol. 352, no. 6330, pp. 33-36, 1991.

[37] D. G. Miller and I. Hampton, "Biology and ecology of the Antarctic krill (Euphausia superba Dana): a review," Biomass Science Series, vol. 9, pp. 1-166, 1989.

[38] K. L. Daly, "Overwintering growth and development of larval Euphausia superba: an interannual comparison under varying environmental conditions west of the Antarctic Peninsula," Deep-Sea Research Part II, vol. 51, no. 17-19, pp. 2139-2168, 2004.

[39] Australian Antarctic Data Centre, "Sea-Ice Extent," Digital media, 2005, http://www.aad.gov.au/.

[40] T. D. Mitchell and P. D. Jones, "An improved method of constructing a database of monthly climate observations and associated high-resolution grids," International Journal of Climatology, vol. 25, no. 6, pp. 693-712, 2005, This dataset (resolution $0.5^{\circ} \mathrm{x} 0.5^{\circ}$ ) is known as CRU TS 2.1 and is publicly, 2005, (http://www.cru.uea.ac.uk/).
[41] C. Torrence and P. J. Webster, "Interdecadal changes in the ENSO-monsoon system," Journal of Climate, vol. 12, no. 8, pp. 2679-2690, 1999.

[42] A. Grinsted, J. C. Moore, and S. Jevrejeva, "Application of the cross wavelet transform and wavelet coherence to geophysical times series," Nonlinear Processes in Geophysics, vol. 11, no. 5-6, pp. 561-566, 2004.

[43] Y. Y. Yoo, D. H. Kim, and J. J. Park, Data Analysis in Oceanography Using Matlab, A-JIN, Seoul, Republic of Korea, 2006.

[44] C. Reiss, "Calibration error in the AMLR plankton time series," CCAMLR, WG-EMM-08/19, pp. 1-9, 2008.

[45] L. B. Quetin, R. M. Ross, T. K. Fraser, and K. L. Haberman, "Factors affecting distribution and abundance of zooplankton, with an emphasis on Antarctic krill, Euphausia superb," Antarctic Research Series, vol. 70, pp. 357-371, 1996.

[46] V. J. Loeb, E. E. Hofmann, J. M. Klinck, O. Holm-Hansen, and W. B. White, "ENSO and variability of the Antarctic peninsula pelagic marine ecosystem," Antarctic Science, vol. 21, no. 2, pp. 135-148, 2009.

[47] R. M. Ross, L. B. Quetin, D. G. Martinson, R. A. Iannuzzi, S. E. Stammerjohn, and R. C. Smith, "Palmer LTER: patterns of distribution of five dominant zooplankton species in the epipelagic zone west of the Antarctic Peninsula, 1993-2004," Deep-Sea Research Part II, vol. 55, no. 18-19, pp. 2086-2105, 2008.

[48] J. Priddle, J. P. Croxall, I. Everson et al., "Large-scale fluctuations in distribution and abundance of krill-a discussion of possible causes," in Antarctic Ocean and Resources Variability, D. Sahrhage, Ed., pp. 169-182, Springer, Berlin, Germany, 1988.

[49] M. P. Meredith and J. C. King, "Rapid climate change in the ocean west of the Antarctic Peninsula during the second half of the 20th century," Geophysical Research Letters, vol. 32, no. 19, Article ID L19604, 5 pages, 2005.

[50] E. Fahrbach, M. Hoppema, G. Rohardt, M. Schröder, and A. Wisotzki, "Decadal-scale variations of water mass properties in the deep Weddell Sea," Ocean Dynamics, vol. 54, no. 1, pp. 77-91, 2004.

[51] S. T. Gille, "Warming of the Southern Ocean since the 1950s," Science, vol. 295, no. 5558, pp. 1275-1277, 2002.

[52] L. H. Smedsrud, "Warming of the deep water in the Weddell Sea along the Greenwich meridian: 1977-2001," Deep-Sea Research Part I, vol. 52, no. 2, pp. 241-258, 2005.

[53] M. Montes-Hugo, S. C. Doney, H. W. Ducklow et al., "Recent changes in phytoplankton communities associated with rapid regional climate change along the western Antarctic Peninsula," Science, vol. 323, no. 5920, pp. 1470-1473, 2009.

[54] M. A. Moline, H. Claustre, T. K. Frazer, O. Schofield, and M. Vernet, "Alteration of the food web along the Antarctic Peninsula in response to a regional warming trend," Global Change Biology, vol. 10, no. 12, pp. 1973-1980, 2004.

[55] W. B. White, S.-C. Chen, R. J. Allan, and R. C. Stone, "Positive feedbacks between the Antarctic Circumpolar Wave and the global El Niño-Southern Oscillation wave," Journal of Geophysical Research C: Oceans, vol. 107, no. 3165, 17 pages, 2002.

[56] A. M. Carleton, "Atmospheric teleconnections involving the Southern Ocean," Journal of Geophysical Research C: Oceans, vol. 108, no. 4, pp. 7-15, 2003.

[57] X. Yuan, "ENSO-related impacts on Antarctic sea ice: a synthesis of phenomenon and mechanisms," Antarctic Science, vol. 16, no. 4, pp. 415-425, 2004. 
[58] J. Kondo, "Volcanic eruptions, cool summers and famines in the Northeastern part of Japan," Journal of Climate, vol. 1, pp. 775-788, 1988.

[59] R. C. Francis and S. R. Hare, "Decadal-scale regime shifts in the large marine ecosystems of the north-east Pacific: a case for historical science," Fisheries Oceanography, vol. 3, no. 4, pp. 279-291, 1994.

[60] J. J. Polovina, G. T. Mitchum, N. E. Graham, M. P. Craig, E. E. DeMartini, and E. N. Flint, "Physical and biological consequences of a climate event in the central North Pacific," Fisheries Oceanography, vol. 3, no. 1, pp. 15-21, 1994.

[61] D. L. Mackas, "Inter-annual variability of the zooplankton community off Southern Vancouver Island," in Climate Change and Northern Fish Populations, R. J. Beamish, Ed., vol. 121, Canadian Special Publication of Fisheries and Aquatic Sciences, 1995.

[62] S. Minobe, "A 50-70 year climatic oscillation over the North Pacific and North America," Geophysical Research Letters, vol. 24, no. 6, pp. 683-686, 1997.

[63] W. J. Ingraham, C. C. Ebbesmeyer, and R. A. Hinrichsen, "Imminent climate and circulation shift in Northeast Pacific Ocean could have major impact on marine resources," EOS, vol. 79, pp. 197-201, 1998.

[64] J. Wiedenmann, K. A. Cresswell, and M. Mangel, “Connecting recruitment of Antarctic krill and sea ice," Limnology and Oceanography, vol. 54, no. 3, pp. 799-811, 2009.

[65] C. I. Lee, E. A. Pakhomov, A. Atkinson, and V. Siegel, "Relationships between marine environment and krill/salp in the Southern Ocean: habitat differences in krill and salp distribution areas," in preparation.

[66] E. A. Pakhomov, "Demography and life cycle of Antarctic krill, Euphausia superba, in the indian sector of the southern ocean: long-term comparison between coastal and openocean regions," Canadian Journal of Fisheries and Aquatic Sciences, vol. 57, supplement 3, pp. 68-90, 2000.

[67] V. Siegel, "Krill (Euphausiacea) life history and aspects of population dynamics," Canadian Journal of Fisheries and Aquatic Sciences, vol. 57, no. 3, pp. 130-150, 2000.

[68] M. P. Meredith, I. A. Renfrew, A. Clarke, J. C. King, and M. A. Brandon, "Impact of the 1997/98 ENSO on upper ocean characteristics in Marguerite Bay, western Antarctic Peninsula," Journal of Geophysical Research C: Oceans, vol. 109, no. 9, Article ID C09013, 19 pages, 2004.

[69] E. J. Murphy, P. N. Trathan, J. L. Watkins et al., "Climatically driven fluctuations in Southern Ocean ecosystems," Proceedings of the Royal Society B: Biological Sciences, vol. 274, no. 1629, pp. 3057-3067, 2007.

[70] W. B. White and R. G. Peterson, "An Antarctic circumpolar wave in surface pressure, wind, temperature and sea-ice extent," Nature, vol. 380, no. 6576, pp. 699-702, 1996.

[71] D. J. Karoly, R. A. Plumb, and M. Ting, "Examples of the horizontal propagation of quasi-stationary waves," Journal of the Atmospheric Sciences, vol. 46, no. 18, pp. 2802-2811, 1989.

[72] E. M. Rasmusson and K. Mo, "Linkages between 200-mb tropical and extratropical circulation anomalies during the 1986-1989 ENSO cycle," Journal of Climate, vol. 6, no. 4, pp. 595-616, 1993.

[73] P. D. Sardeshmukh and B. J. Hoskins, "The generation of global rotational flow by steady idealized tropical divergence," Journal of the Atmospheric Sciences, vol. 45, no. 7, pp. 1228 1251, 1988.

[74] X. Yuan and D. G. Martinson, "The Antarctic dipole and its predictability," Geophysical Research Letters, vol. 28, no. 18, pp. 3609-3612, 2001.
[75] W. B. White and J. Annis, "Influence of the Antarctic Circumpolar Wave on El Niño and its multidecadal changes from 1950 to 2001," Journal of Geophysical Research C: Oceans, vol. 109, no. 6, Article ID C06019, 18 pages, 2004.

[76] M. A. Moline, N. J. Karnovsky, Z. Brown et al., "High latitude changes in ice dynamics and their impact on polar marine ecosystems," Annals of the New York Academy of Sciences, vol. 1134, pp. 267-319, 2008.

[77] S. S. Jacobs and J. C. Comiso, "A recent sea-ice retreat west of the Antarctic Peninsula," Geophysical Research Letters, vol. 20, no. 12, pp. 1171-1174, 1993.

[78] A. Shepherd, D. J. Wingham, J. A. D. Mansley, and H. F. J. Corr, "Inland thinning of Pine Island Glacier, West Antarctica," Science, vol. 291, no. 5505, pp. 862-864, 2001.

[79] A. Shepherd, D. Wingham, and E. Rignot, "Warm ocean is eroding West Antarctic Ice Sheet," Geophysical Research Letters, vol. 31, no. 23, Article ID L23402, 4 pages, 2004.

[80] E. Rignot and S. S. Jacobs, "Rapid bottom melting widespread near Antarctic ice sheet grounding lines," Science, vol. 296, no. 5575, pp. 2020-2023, 2002. 

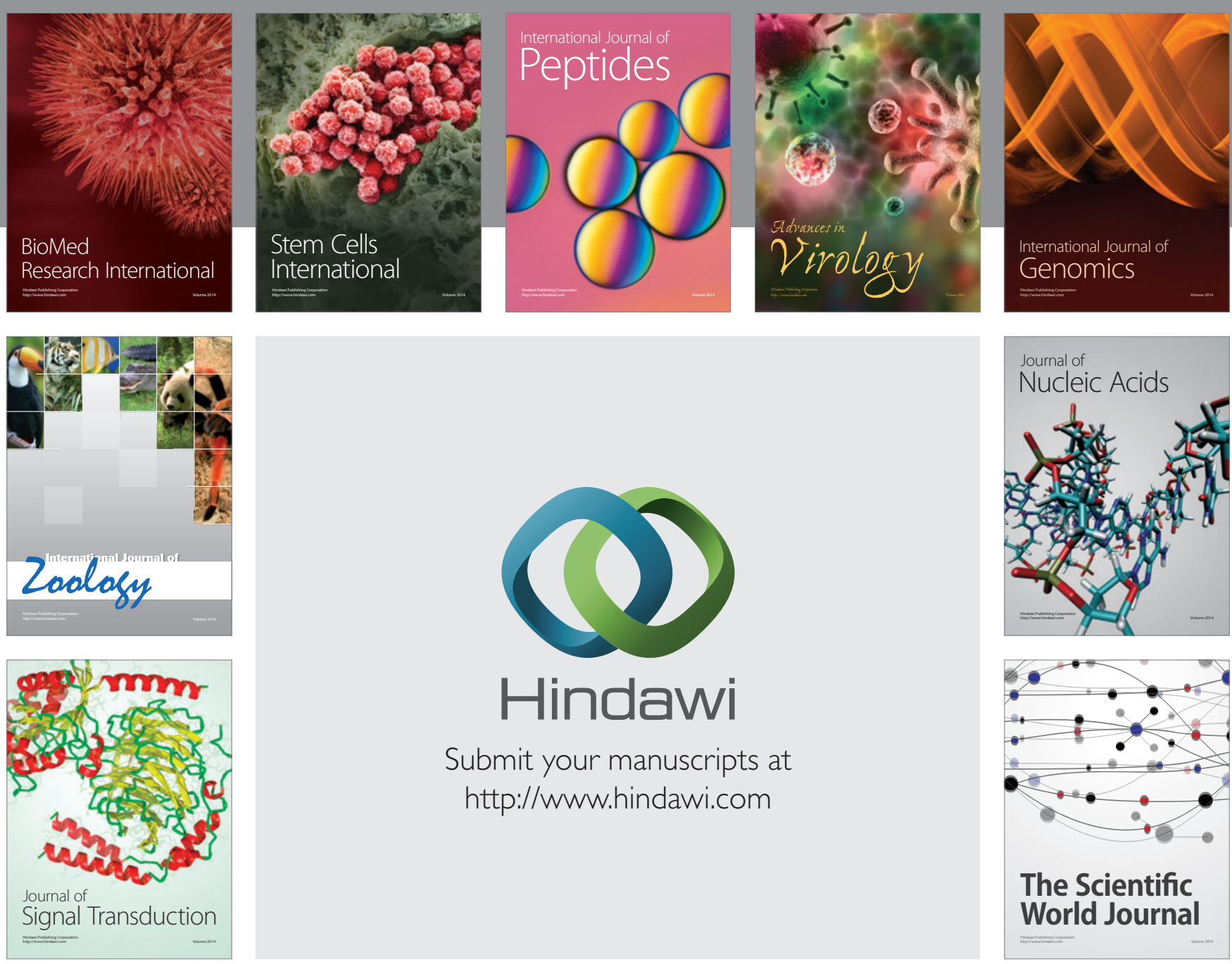

Submit your manuscripts at

http://www.hindawi.com
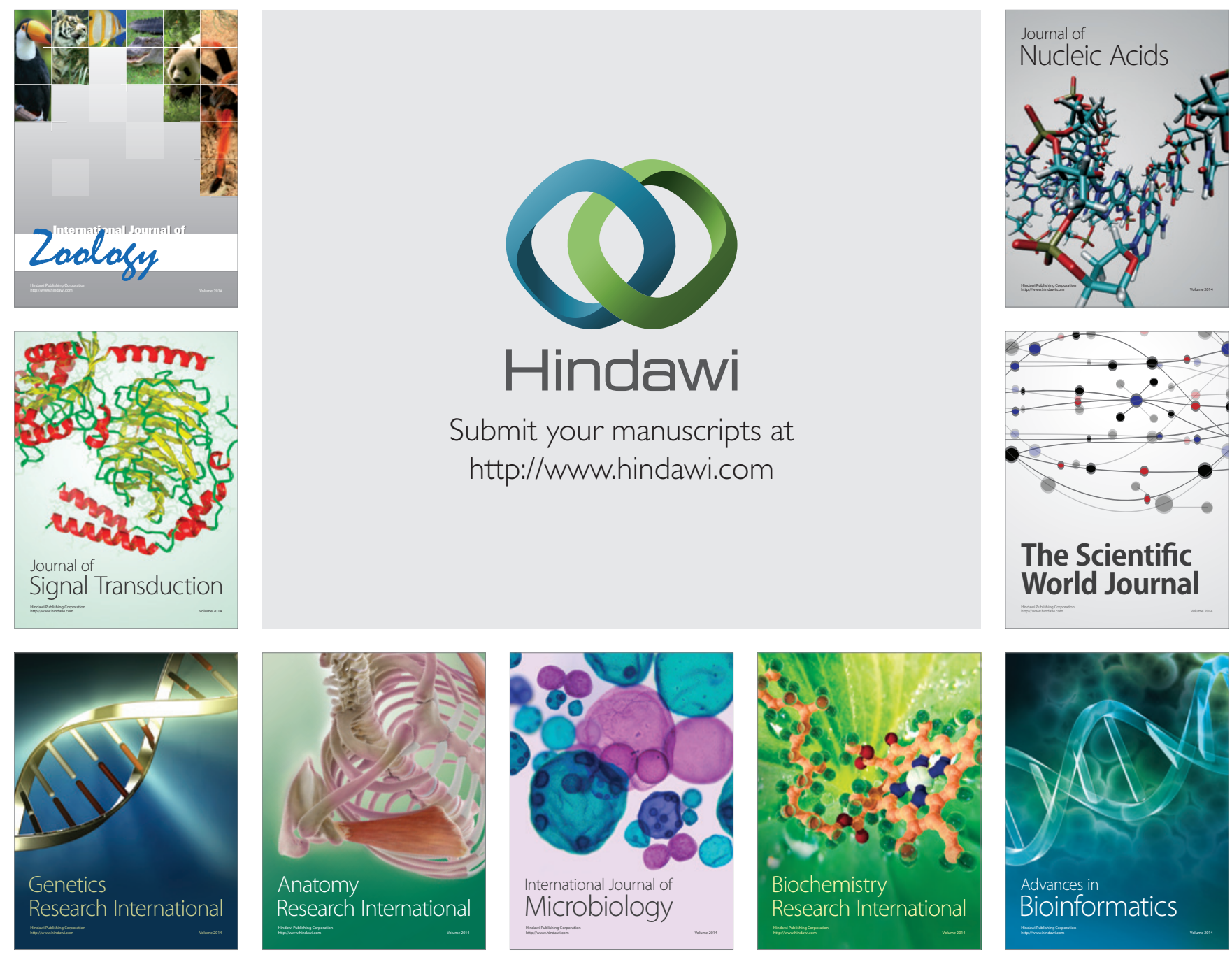

The Scientific World Journal
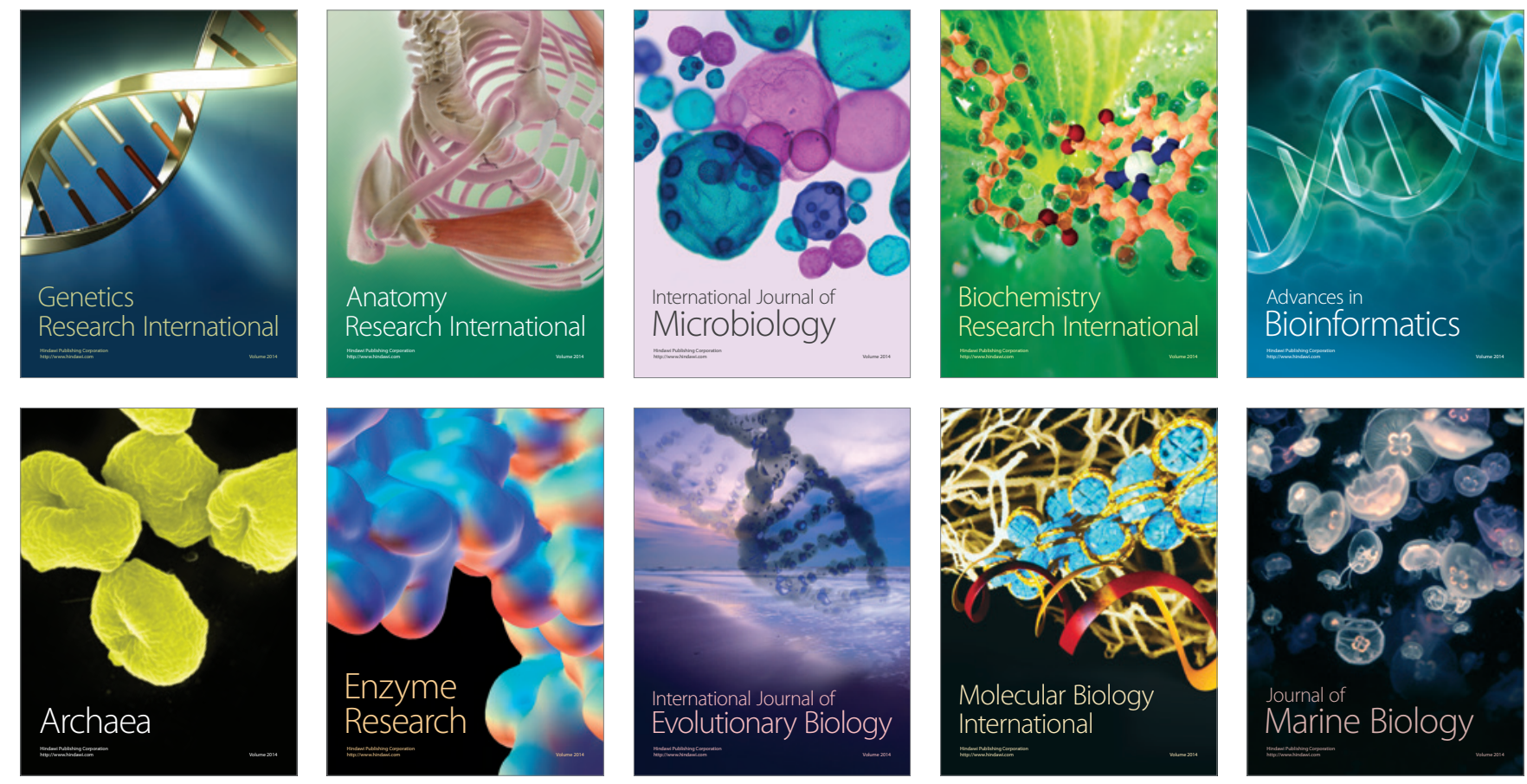